\title{
Transition probabilities and lifetimes in neutral and singly ionized osmium and the Solar osmium abundance ${ }^{\star, \star \star}$
}

\author{
P. Quinet ${ }^{1,2}$, P. Palmeri ${ }^{2}$, É. Biémont ${ }^{1,2}$, A. Jorissen ${ }^{3}$, S. Van Eck ${ }^{3}$, S. Svanberg ${ }^{4}$, H. L. Xu ${ }^{4}$, and B. Plez ${ }^{5}$
}

1 IPNAS, Université de Liège, Sart Tilman B15, 4000 Liège, Belgium

e-mail: E.Biemont@ulg.ac.be

2 Astrophysique et Spectroscopie, Université de Mons-Hainaut, 7000 Mons, Belgium

e-mail: Pascal.quinet@umh.ac.be

3 Institut d'Astrophysique, Université Libre de Bruxelles, 1050 Bruxelles, Belgium

e-mail: [ajorisse; svaneck] @astro.ulb.ac.be

4 Department of Physics, Lund Institute of Technology, PO Box 118, 22100 Lund, Sweden e-mail: Sune. Svanberg@fysik.lth.se

5 GRAAL, CNRS UMR 5024, Université Montpellier II, 34095 Montpellier Cedex 5, France

e-mail: bertrand.plez@graal.univ-montp2.fr

Received 19 July 2005 / Accepted 14 October 2005

\section{ABSTRACT}

Radiative lifetime measurements have been performed, with a time-resolved laser-induced fluorescence technique, for 12 levels of Os I and for 9 levels of Os II. For 9 levels of Os I and 4 levels of Os II, there were no previous experimental data available. From a comparison with new theoretical calculations, taking configuration interactions and core-polarization effects into account, it has been possible to deduce oscillator strengths for 129 transitions of Os I and 137 transitions of Os II of astrophysical interest appearing in the wavelength range 180.0-870.0 nm. These results have allowed us to revise the abundance of osmium in the solar photosphere $\left(\log \varepsilon_{\mathrm{Os}}=1.25 \pm 0.11\right)$. The newly derived oscillator strengths have been applied as well to derive the osmium abundance in the carbon-rich metal-poor star HD 187861.

Key words. Sun: abundances - atomic data - atomic processes

\section{Introduction}

Osmium was discovered by S. Tennant, in London, in 1803. This heavy $(Z=76)$ element has seven stable isotopes in the solar system i.e. $192,190,189,188,187,186$ and 184 with abundances of $41.0,26.4,16.1,13.3,1.6,1.6$ and $0.02 \%$, respectively. In addition, 12 unstable isotopes and isomers are known. In astrophysics, the most abundant isotopes (192, 190 and 189) are produced by the $r$ process (rapid capture of neutrons). ${ }^{187}$ Os and ${ }^{186}$ Os are generated by pure s process (slow capture of neutrons) while ${ }^{188} \mathrm{Os}$ is produced by both the $\mathrm{r}$ and s processes.

Os I has been identified in stellar spectra a long time ago. It has been observed in M 2 III stars (Davis 1947) and both Os I and Os II have been identified in some peculiar Ap stars (see e.g. Guthrie 1969; Brandi \& Jaschek 1970; Cowley 1987). Recently, the Os I spectrum was reinvestigated in the star CS 31082-001 (Ivarsson et al. 2003) and Os II was

\footnotetext{
* Based on observations obtained with the ESO VLT under ESO programme ID 90.D-0063A.

$\star \star$ Tables 5 and 6 are only available in electronic form at http://www.edpsciences.org
}

studied in the spectrum of the $\mathrm{HgMn} \chi$ Lupi star (Ivarsson et al. 2004).

At low-metallicity, a large variety of heavy element abundance patterns is observed: some stars are found to be enriched either in r-elements, or in s-elements, or even in both. Osmium is a key element since it is predominantly synthetized by the r-process. For pure r-process-enriched stars, investigating the osmium content is thus of great significance in radioactive cosmochronology and for imposing constraints on the structure and nucleosynthesis yields of supernovae from the first stellar generation (Ivarsson et al. 2003). Even for s-process-enriched stars, it is interesting to derive the osmium abundance, since it traces the r-component and allows one to identify new members of the emerging class of s-r-enriched stars. In fact, testing nucleosynthesis models of the heaviest elements in low-metallicity stars places strong demands on the radiative parameters required to convert measured equivalent widths of stellar lines into accurate absolute abundances.

Transition probabilities in Os I and Os II spectra are still very sparse. In Os I, the only $\mathrm{f}$ values available are those of Corliss \& Bozman (1962) (arc measurements), those derived from the lifetime measurements of Kwiatkowski et al. (1984) 
and a recent determination for 18 transitions by Ivarsson et al. (2003). Some compilations have also been reported by Doidge (1995, 1996) for resonance lines and by Morton (2000, 2001) for transitions of astrophysical interest longward of the Lyman limit. In Os II, the Corliss \& Bozman (1962) measurements have been superseded by more accurate results obtained by Leckrone et al. (1999) and, more recently, by Ivarsson et al. (2004). In the latter case, oscillator strengths of 27 Os II transitions have been determined by combining radiative lifetimes using the laser-induced fluorescence (LIF) technique with branching fractions (BF) determined from Fourier transform spectrometer emission line intensities.

In view of this gap of transition probabilities and of the need in astrophysics for investigating the chemical composition of some peculiar stars, we present a new set of results in both Os I and Os II. In the present paper, radiative lifetime measurements have been performed with a LIF approach for 12 levels of Os I and for 9 levels of Os II. From a combination of theoretical BFs and experimental lifetime values, new oscillator strengths have been deduced for a set of transitions of astrophysical interest appearing in the wavelength range $180.0-870.0 \mathrm{~nm}$.

The new results have allowed us to review the solar photospheric abundance of osmium.

\section{Atomic structure and spectra of Os I and Os II}

Partly in relation with the low cosmic abundance of osmium, our knowledge of the spectrum of this element is still rather fragmentary. Some regularities in Os I were observed very early by Meggers \& Laporte (1926). The NBS compilation of Os I energy levels (Moore 1958) was based on early measurements by Albertson $(1934,1938)$ registered at the Massachussetts Institute of Technology (MIT) (4500 lines among which 2169 were classified as combinations among 234 levels). Additional measurements were made at the MIT by Van den Bosch who made Zeeman spectrograms and who, in collaboration with van Kleef, extended the spectrum of Os I (Van den Bosch 1955; Van den Bosch \& van Kleef 1956) (about 6000 lines among which 2387 were classified as belonging to combinations from 257 levels). For Os II, the NBS compilation (Moore 1958) was also based on van den Bosch's unpublished material (1956). A further revision of the Os I spectrum analysis led Van Kleef (1960) to reject 14 levels from the level list and to add 18 new levels. A summary of the data available in Os I and Os II spectra was published by Van Kleef \& Klinkenberg (1961). About $40 \%$ of the total of the lines of Os I and only $15 \%$ of the total of the lines of Os II have been classified. Level designation (at least partial designation) was provided for 263 Os I and 43 Os II levels. A parametric study of the $(5 d+6 s)^{8}$ configurations, performed by Gluck et al. (1964) and Gluck (1965), has allowed the identification of the lowest term ${ }^{3} \mathrm{~F}$ of the $5 \mathrm{~d}^{8}$ configuration and the assignement of a prominent configuration to the 49 low even levels. The finestructure parameters, as determined with the Slater-Condon method, by Gluck et al. (1964), agree with those provided by Wyart (1978) and Blaise \& Wyart (1989). The MIT Wavelength Tables (Harrison 1939) contain 1745 osmium lines in the domain 200.0 to $804.2 \mathrm{~nm}$ and 1036 lines have been listed by Meggers et al. (1975) in the emission spectrum of a copper arc.

The nuclear spin $I=1 / 2$ for ${ }^{187}$ Os (Murakawa 1955; Guthörhlein et al. 1961), 3/2 for ${ }^{189}$ Os (Murakawa \& Suwa 1952; Loeliger \& Sarles 1954) and $I=0$ for the even isotopes, indicate that hyperfine structure effects are likely to appear only for the first two isotopes. Hyperfine structure measurements, with natural abundances of the isotopes, have been published by Kawada (1938), Suwa (1951), Murakawa \& Suwa (1952), Murakawa (1955), Murakawa \& Kamei (1957) and Blaise (1957, 1958). Further measurements, using radiogenic Os-enriched samples, were performed by Guthörhlein et al. (1961, 1969) and by Himmel (1968). The hyperfine structure and isotope shifts of many levels and lines in Os I were investigated by Kröger et al. (2002) using LIF spectroscopy.

Isotope shifts are indeed present in the Os spectrum. Measurements with natural osmium are due to Kawada (1938), Suwa (1951), Murakawa \& Suwa (1952) and Murakawa (1955). Later on, measurements with isotopically enriched osmium were reported by Guthörhlein et al. (1961), Hines \& Ross (1962), Nöldeke \& Saksena (1962), Nöldeke et al. (1962) and Aufmuth \& Wöbker (1985). More detailed discussions on both hyperfine structures and isotope shifts have been provided by Blaise \& Wyart (1989).

\section{Experimental method}

In the present work, some lifetime measurements were performed with a method of selective excitation of an atomic or ionic plasma by a tunable laser radiation and time-resolved detection of the fluorescence emitted from the decaying levels. The experimental apparatus used in the present work is schematically shown in Fig. 1. Free neutral and singly ionized osmium atoms were obtained by focusing a pulsed $532 \mathrm{~nm}$ Nd:YAG laser (Continuum Surelite) (Laser A in Fig. 1) beam onto a pure Os foil, rotating in a vacuum chamber with about $10^{-6}-10^{-5}$ mbar background pressure. The pulse of the ablation laser had a duration of $10 \mathrm{~ns}$ and a repetition rate of $10 \mathrm{~Hz}$. The pulse energy was in the range of 2-10 $\mathrm{mJ}$. After the hitting of the laser pulse on the osmium foil, a plasma containing neutral as well as ionized atoms was produced and expanded from the foil for subsequent laser excitation. The laser-produced plasma has the advantage of high atomic and ionic populations in ground as well as in metastable states, which can be used as a starting point for laser excitation, as presented in Tables 1 and 2. Another advantage of this technique is that the plasma density and temperature can be easily controlled and adjusted by changing the pulse energy and beam size on the foil, and also the delay time between the ablation and the excitation pulses.

In order to obtain the excitation radiation, a 532-nm laser pulse, emitted from the second Nd:YAG laser (Continuum NY-82) (Laser B in Fig. 1) with an 8-ns pulse duration, a single pulse energy of $400 \mathrm{~mJ}$ and a repetition rate of $10 \mathrm{~Hz}$, was first sent into a stimulated Brillouin scattering (SBS) cell to compress the pulse duration (Schiemann et al. 1998; $\mathrm{Xu}$ et al. 2004). The pulse duration of the output from the SBS temporal compressor could be shortened to about $1 \mathrm{~ns}$. 


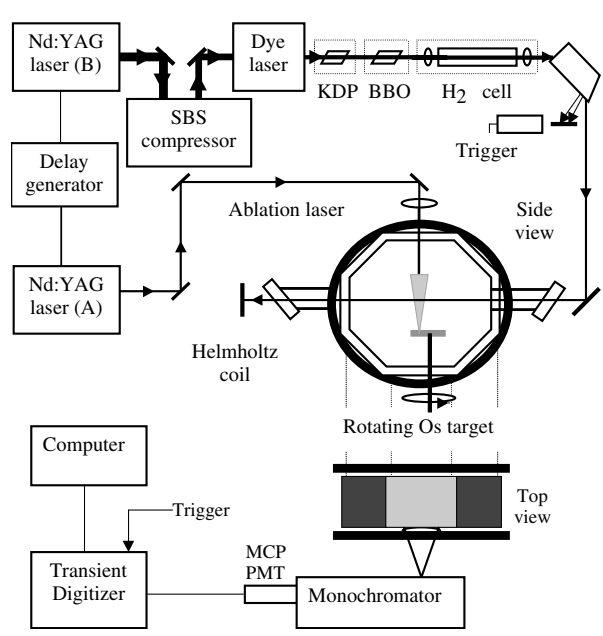

Fig. 1. Experimental device.

The compressed laser pulse was then employed to pump a dye laser (Continuum Nd-60), in which a DCM dye was operating. The radiation from the dye laser was frequency doubled in a KDP crystal and then mixed with the fundamental frequency in a BBO crystal, to generate the third harmonic of the dye laser frequency. The second or the third harmonic of the dye laser beam was focused onto a $\mathrm{H}_{2}$ cell at 10 bars, in which different orders of stimulated Stokes and anti-Stokes scattering were obtained. Depending on the excitation requirements, the appropriate frequency component of the output from the $\mathrm{H}_{2}$ cell was selected with a $\mathrm{CaF}_{2}$ prism, and was then horizontally sent into the vacuum chamber. The excitation beam interacted with the neutral or singly ionized Os atoms about $1 \mathrm{~cm}$ above the foil. The fluorescence, emitted from the excited levels, was collected by a fused-silica lens and focused onto the entrance slit of a $1 / 8 \mathrm{~m}$ focal length monochromator. The fluorescence was detected by a Hamamatsu $1564 \mathrm{U}$ micro-channel-plate (MCP) photomultiplier tube (PMT) with a risetime of $0.2 \mathrm{~ns}$. The MCP PMT was connected to a transient recorder (Tektronix Model DSA 602), which had a $1 \mathrm{GHz}$ bandwidth and a $2 \mathrm{G}$ samples/s real-time sampling rate. The temporal shape of the excitation pulses was also recorded for short-lived states of Os I and Os II with the same detection system by inserting a metal rod into the interaction zone of the excitation laser and the plasma while the ablation beam was blocked.

\section{Measurements and results}

The ground state configurations of Os I and Os II are $5 d^{6} 6 s^{2}$ and $5 d^{6} 6 s$, respectively. The laser excitation was performed using a single-step process from the ground or from the low lying metastable states of Os I and Os II, and the excitation lines emitted from the studied states were located in the spectral range $213-443 \mathrm{~m}$, which can be covered by different non-linear processes $(2 \omega+2 \mathrm{~S}, 2 \omega+\mathrm{S}, 2 \omega+\mathrm{A}, 3 \omega+\mathrm{S}$ and $3 \omega)$ using the DCM dye. Twelve odd-parity levels of Os I in the energy range from 22615 to $46777 \mathrm{~cm}^{-1}$ and 9 odd levels of Os II in the range 39389 to $54446 \mathrm{~cm}^{-1}$ were measured. They belong to the $5 d^{6} 6 s 6 p$ and $5 d^{7} 6 p$ configurations (Os I) and to the $5 d^{5} 6 s 6 p$
Table 1. Measured levels and excitation schemes in Os II.

\begin{tabular}{cccccc}
\hline \hline Config. & Term & $J$ & $E\left(\mathrm{~cm}^{-1}\right)$ & Origin & $\begin{array}{c}\text { Obs. } \\
\lambda_{\text {air }}(\mathrm{nm})\end{array}$ \\
\hline $5 \mathrm{~d}^{5} 6 \mathrm{~s}\left({ }^{7} \mathrm{~S}\right) 6 \mathrm{p}$ & ${ }^{8} \mathrm{P}^{\circ}$ & $7 / 2$ & 39389.49 & 0.0 & 317 \\
$5 \mathrm{~d}^{6}\left({ }^{5} \mathrm{D}\right) 6 \mathrm{p}$ & ${ }^{6} \mathrm{D}^{\circ}$ & $7 / 2$ & 43802.36 & 0.0 & \\
$5 \mathrm{~d}^{6}\left({ }^{5} \mathrm{D}\right) 6 \mathrm{p}$ & ${ }^{6} \mathrm{D}^{\circ}$ & $9 / 2$ & 44315.40 & 0.0 & 321 \\
$5 \mathrm{~d}^{6}\left({ }^{5} \mathrm{D}\right) 6 \mathrm{p}$ & ${ }^{6} \mathrm{D}^{\circ}$ & $5 / 2$ & 46373.51 & 3593.15 & 287 \\
$5 \mathrm{~d}^{5} 6 \mathrm{~s}\left({ }^{7} \mathrm{~S}\right) 6 \mathrm{p}$ & ${ }^{6} \mathrm{P}^{\circ}$ & $7 / 2$ & 49149.39 & 3593.15 & 242 \\
$5 \mathrm{~d}^{6}\left({ }^{5} \mathrm{D}\right) 6 \mathrm{p}$ & ${ }^{6} \mathrm{~F}^{\circ}$ & $9 / 2$ & 51951.61 & 3593.15 & 258 \\
$5 \mathrm{~d}^{6}\left({ }^{5} \mathrm{D}\right) 6 \mathrm{p}$ & ${ }^{6} \mathrm{~F}^{\circ}$ & $7 / 2$ & 52206.48 & 3928.94 & 256 \\
$5 \mathrm{~d}^{6}\left({ }^{5} \mathrm{D}\right) 6 \mathrm{p}$ & ${ }^{4} \mathrm{~F}^{\circ}$ & $7 / 2$ & 54379.27 & 7891.93 & 258 \\
$5 \mathrm{~d}^{6}\left({ }^{5} \mathrm{D}\right) 6 \mathrm{p}$ & ${ }^{4} \mathrm{D}^{\circ}$ & $5 / 2$ & 54445.19 & 7891.93 & 242 \\
\hline
\end{tabular}

Table 2. Measured levels and excitation schemes in Os I.

\begin{tabular}{ccccccc}
\hline \hline Config. & Term & $J$ & $E\left(\mathrm{~cm}^{-1}\right)$ & Origin & $\begin{array}{c}\text { Exc. } \\
\lambda_{\text {air }}(\mathrm{nm})\end{array}$ & $\begin{array}{c}\text { Obs. } \\
\lambda_{\text {air }}(\mathrm{nm})\end{array}$ \\
\hline $5 \mathrm{~d}^{6} 6 \mathrm{~s}\left({ }^{6} \mathrm{D}\right) 6 \mathrm{p}$ & ${ }^{7} \mathrm{D}^{\circ}$ & 4 & 22615.69 & 0.0 & 442.05 & 442 \\
$5 \mathrm{~d}^{6} 6 \mathrm{~s}\left({ }^{6} \mathrm{D}\right) 6 \mathrm{p}$ & ${ }^{7} \mathrm{P}^{\circ}$ & 4 & 28331.77 & 0.0 & & \\
$5 \mathrm{~d}^{6} 6 \mathrm{~s}\left({ }^{6} \mathrm{D}\right) 6 \mathrm{p}$ & ${ }^{7} \mathrm{P}^{\circ}$ & 3 & 28371.68 & 0.0 & 352.36 & 352 \\
$5 \mathrm{~d}^{6} 6 \mathrm{~s}\left({ }^{6} \mathrm{D}\right) 6 \mathrm{p}$ & ${ }^{7} \mathrm{P}^{\circ}$ & 4 & 30591.45 & 0.0 & 326.79 & 378 \\
$5 \mathrm{~d}^{6} 6 \mathrm{~s}\left({ }^{6} \mathrm{D}\right) 6 \mathrm{p}$ & ${ }^{7} \mathrm{P}^{\circ}$ & 3 & 33124.48 & 2740.49 & 329.03 & 302 \\
$5 \mathrm{~d}^{6} 6 \mathrm{~s}\left({ }^{6} \mathrm{D}\right) 6 \mathrm{p}$ & ${ }^{5} \mathrm{~F}^{\circ}$ & 5 & 34365.33 & 0.0 & & \\
$5 \mathrm{~d}^{6} 6 \mathrm{~s}\left({ }^{6} \mathrm{D}\right) 6 \mathrm{p}$ & ${ }^{5} \mathrm{~F}^{\circ}$ & 4 & 34803.82 & 0.0 & 287.24 & 326 \\
$5 \mathrm{~d}^{6} 6 \mathrm{~s}\left({ }^{6} \mathrm{D}\right) 6 \mathrm{p}$ & ${ }^{5} \mathrm{P}^{\circ}$ & 3 & 35615.92 & 0.0 & 280.69 & 304 \\
$5 \mathrm{~d}^{6} 6 \mathrm{~s}\left({ }^{6} \mathrm{D}\right) 6 \mathrm{p}$ & ${ }^{5} \mathrm{D}^{\circ}$ & 4 & 36826.39 & 8742.83 & 355.98 & 271 \\
$5 \mathrm{~d}^{6} 6 \mathrm{~s}\left({ }^{4} \mathrm{D}\right) 6 \mathrm{p}$ & ${ }^{5} \mathrm{D}^{\circ}$ & 4 & 37908.77 & 0.0 & 263.71 & 263 \\
$5 \mathrm{~d}^{6} 6 \mathrm{~s}\left({ }^{4} \mathrm{D}\right) 6 \mathrm{p}$ & ${ }^{3} \mathrm{~F}^{\circ}$ & 4 & 40361.92 & 4159.32 & 276.14 & 284 \\
$5 \mathrm{~d}^{7}\left({ }^{4} \mathrm{~F}\right) 6 \mathrm{p}$ & ${ }^{3} \mathrm{D}^{\circ}$ & 3 & 46776.29 & 0.0 & 213.72 & 227 \\
\hline
\end{tabular}

and $5 d^{6} 6 p$ configurations (Os II). Tables 1 and 2 summarize the measured levels and the excitation schemes.

The lifetimes are reported in Tables 3 (Os I) and 4 (Os II) where they are compared with previous experimental results as well as with the theoretical values calculated in this work (see further). In Os I, our LIF measurements agree very well (within the error bars: see Table 3), as expected, with the previous laser measurements by Kwiatkowski et al. (1984) and Ivarsson et al. (2003). A very nice agreement (within the experimental uncertainties) with the measurements of Ivarsson et al. (2004) is also observed for Os II (see Table 4).

Different fitting procedures were adopted for the evaluation of the lifetimes. For the lifetimes longer than $10 \mathrm{ns,} \mathrm{a} \mathrm{least-}$ squares exponential fitting procedure was applied to the decay curves when the excitation pulse had vanished, as shown in Fig. 2. On the other hand, for lifetimes shorter than $10 \mathrm{~ns}$, the evaluation process was performed by fitting the experimental fluorescence decay curve to a convoluted profile resulting from the detected excitation pulse and a pure exponential function, as shown in Fig. 3. In this process, the effects of the finite duration of the excitation pulse and the limited time-response of the detection system could be taken into account because the 
Table 3. Experimental and theoretical radiative lifetimes (in ns) for odd-parity levels of Os I.

\begin{tabular}{ccccccc}
\hline \hline$E\left(\mathrm{~cm}^{-1}\right)$ & Config. & $J$ & $\begin{array}{c}\text { Expt } \\
\text { Previous }\end{array}$ & $\begin{array}{c}\text { Expt } \\
\text { This work }\end{array}$ & HFR $^{c}$ & HFR + CP \\
\hline 22615.69 & $5 \mathrm{~d}^{6} 6 \mathrm{~s}\left({ }^{6} \mathrm{D}\right) 6 \mathrm{p}{ }^{7} \mathrm{D}^{\circ}$ & 4 & & $400 \pm 50$ & 411 & 540 \\
28331.77 & $5 \mathrm{~d}^{6} 6 \mathrm{~s}\left({ }^{6} \mathrm{D}\right) 6 \mathrm{p}{ }^{7} \mathrm{P}^{\circ}$ & 4 & $238 \pm 12^{a}$, & $230 \pm 20$ & 149 & 200 \\
& & & $265 \pm 20^{b}$ & & & \\
28371.68 & $5 \mathrm{~d}^{6} 6 \mathrm{~s}\left({ }^{6} \mathrm{D}\right) 6 \mathrm{p}{ }^{7} \mathrm{P}^{\circ}$ & 3 & & $390 \pm 50$ & 374 & 538 \\
30279.95 & & 5 & $93 \pm 7^{b}$ & & & \\
30591.45 & $5 \mathrm{~d}^{6} 6 \mathrm{~s}\left({ }^{6} \mathrm{D}\right) 6 \mathrm{p}{ }^{7} \mathrm{P}^{\circ}$ & 4 & $98 \pm 8^{a}$ & $98 \pm 8$ & 106 & 135 \\
32684.61 & & 4 & $28 \pm 2^{b}$ & & & \\
33124.48 & $5 \mathrm{~d}^{6} 6 \mathrm{~s}\left({ }^{6} \mathrm{D}\right) 6 \mathrm{p}{ }^{7} \mathrm{P}^{\circ}$ & 3 & & $51 \pm 4$ & 65 & 85 \\
34365.33 & $5 \mathrm{~d}^{6} 6 \mathrm{~s}\left({ }^{6} \mathrm{D}\right) 6 \mathrm{p}{ }^{5} \mathrm{~F}^{\circ}$ & 5 & $24 \pm 2^{a, b}$ & $25 \pm 2$ & 18 & 23 \\
34803.82 & $5 \mathrm{~d}^{6} 6 \mathrm{~s}\left({ }^{6} \mathrm{D}\right) 6 \mathrm{p}{ }^{5} \mathrm{~F}^{\circ}$ & 4 & & $58 \pm 5$ & 46 & 59 \\
35615.92 & $5 \mathrm{~d}^{6} 6 \mathrm{~s}\left({ }^{6} \mathrm{D}\right) 6 \mathrm{p}{ }^{5} \mathrm{P}^{\circ}$ & 3 & & $31 \pm 2$ & 33 & 38 \\
36826.39 & $5 \mathrm{~d}^{6} 6 \mathrm{~s}\left({ }^{6} \mathrm{D}\right) 6 \mathrm{p}{ }^{5} \mathrm{D}^{\circ}$ & 4 & & $45 \pm 4$ & 82 & 109 \\
37908.77 & $5 \mathrm{~d}^{6} 6 \mathrm{~s}\left({ }^{4} \mathrm{D}\right) 6 \mathrm{p}{ }^{5} \mathrm{D}^{\circ}$ & 4 & & $28 \pm 2$ & 14 & 18 \\
40361.92 & $5 \mathrm{~d}^{6} 6 \mathrm{~s}\left({ }^{4} \mathrm{D}\right) 6 \mathrm{p}{ }^{3} \mathrm{~F}^{\circ}$ & 4 & & $8.5 \pm 0.7$ & 6.4 & 9.1 \\
46776.29 & $5 \mathrm{~d}^{7}\left({ }^{4} \mathrm{~F}\right) 6 \mathrm{p}{ }^{3} \mathrm{D}^{\circ}$ & 3 & & $4.8 \pm 0.3$ & 4.2 & 5.9 \\
\hline
\end{tabular}

${ }^{a}$ Kwiatkowski et al. (1984); ${ }^{b}$ Ivarsson et al. (2003); ${ }^{c}$ Present work.

Table 4. Experimental and theoretical radiative lifetimes (in ns) for odd-parity levels of Os II.

\begin{tabular}{cccccc}
\hline \hline$E\left(\mathrm{~cm}^{-1}\right)^{a}$ & Config. ${ }^{a}$ & $J$ & $\begin{array}{c}\text { Expt } \\
\text { Previous }\end{array}$ & $\begin{array}{c}\text { Expt } \\
\text { This work }\end{array}$ & $\begin{array}{c}\text { Theory } \\
\text { This work }{ }^{d}\end{array}$ \\
\hline 39389.49 & $5 \mathrm{~d}^{5} 6 \mathrm{~s}\left({ }^{7} \mathrm{~S}\right) 6 \mathrm{p}^{8} \mathrm{P}^{\circ}$ & $7 / 2$ & $68 \pm 5$ & $66 \pm 6$ & 198 \\
41282.95 & $5 \mathrm{~d}^{5} 6 \mathrm{~s}\left({ }^{7} \mathrm{~S}\right) 6 \mathrm{p}^{8} \mathrm{P}^{\circ}$ & $9 / 2$ & & & 122 \\
43802.36 & $5 \mathrm{~d}^{6}\left({ }^{5} \mathrm{D}\right) 6 \mathrm{p}{ }^{6} \mathrm{D}^{\circ}$ & $7 / 2$ & $5.9 \pm 0.5$ & $5.3 \pm 0.4$ & 5.7 \\
44315.40 & $5 \mathrm{~d}^{6}\left({ }^{5} \mathrm{D}\right) 6 \mathrm{p}{ }^{6} \mathrm{D}^{\circ}$ & $9 / 2$ & & $5.1 \pm 0.4$ & 5.1 \\
46157.19 & $5 \mathrm{~d}^{6}\left({ }^{5} \mathrm{D}\right) 6 \mathrm{p}{ }^{6} \mathrm{D}^{\circ}$ & $3 / 2$ & $5.6 \pm 0.5$ & & 5.8 \\
46373.51 & $5 \mathrm{~d}^{6}\left({ }^{5} \mathrm{D}\right) 6 \mathrm{p}{ }^{6} \mathrm{D}^{\circ}$ & $5 / 2$ & $5.6 \pm 0.5$ & $6.0 \pm 0.6$ & 5.6 \\
48128.08 & $5 \mathrm{~d}^{6}\left({ }^{5} \mathrm{D}\right) 6 \mathrm{p}{ }^{6} \mathrm{D}^{\circ}$ & $1 / 2$ & $5.9 \pm 0.5$ & & 5.6 \\
48798.70 & $5 \mathrm{~d}^{6}\left({ }^{5} \mathrm{D}\right) 6 \mathrm{p}{ }^{6} \mathrm{~F}^{\circ}$ & $5 / 2$ & $6.7 \pm 0.5$ & & 7.4 \\
49149.39 & $5 \mathrm{~d}^{5} 6 \mathrm{~s}\left({ }^{7} \mathrm{~S}\right) 6 \mathrm{p}{ }^{6} \mathrm{P}^{\circ}$ & $7 / 2$ & & $6.7 \pm 0.6$ & 6.4 \\
51770.38 & $5 \mathrm{~d}^{5} 6 \mathrm{~s}\left({ }^{7} \mathrm{~S}\right) 6 \mathrm{p}{ }^{6} \mathrm{P}^{\circ}$ & $5 / 2$ & & & 3.2 \\
51951.61 & $5 \mathrm{~d}^{6}\left({ }^{5} \mathrm{D}\right) 6 \mathrm{p}{ }^{6} \mathrm{~F}^{\circ}$ & $9 / 2$ & $3.2 \pm 0.3$ & $3.2 \pm 0.3$ & 4.6 \\
52206.48 & $5 \mathrm{~d}^{6}\left({ }^{5} \mathrm{D}\right) 6 \mathrm{p}{ }^{6} \mathrm{~F}^{\circ}$ & $7 / 2$ & $4.7 \pm 0.4$ & $4.9 \pm 0.4$ & 4.3 \\
54379.27 & $5 \mathrm{~d}^{6}\left({ }^{5} \mathrm{D}\right) 6 \mathrm{p}{ }^{4} \mathrm{~F}^{\circ}$ & $7 / 2$ & & $4.0 \pm 0.4$ & 4.0 \\
54445.19 & $5 \mathrm{~d}^{6}\left({ }^{5} \mathrm{D}\right) 6 \mathrm{p}{ }^{4} \mathrm{D}^{\circ}$ & $5 / 2$ & & $4.2 \pm 0.4$ & \\
\hline
\end{tabular}

${ }^{a}$ Van Kleef \& Klinkenberg (1961); ${ }^{b}$ Ivarsson et al. (2004); ${ }^{c}$ LIF measurements (see text); ${ }^{d}$ HFR calculations (see text).

recorded excitation curve included both contributions (i.e. the real laser pulse and also the time-response function).

In the measurements, all possible systematic errors susceptible to affect the lifetime results were carefully investigated. It can be seen in Table 3 that the Os I lifetimes of the 22615.69 and $28371.68 \mathrm{~cm}^{-1}$ levels are very long. Therefore, special attention has been paid to flight-out-of-view effects by adjusting the position of the entrance slit of the monochromator and the delay times between the ablation and the excitation pulses. Moreover, the entrance slit of the monochromator was put perpendicularly and parallel to the direction of plasma movement. When the delay time was $5 \mu \mathrm{s}$, velocities of neutral osmium atoms in the interaction area were about $2 \mathrm{~km} \mathrm{~s}^{-1}$. For a very long lifetime $\left(22615.69 \mathrm{~cm}^{-1}\right.$ level, $\tau=$ $400 \mathrm{~ns}$ ), it was desirable to observe the decay at $1.6 \mu \mathrm{s}$, which corresponds to 4 times the lifetime values. The atom flight distance was then $3.2 \mathrm{~mm}$ along the vertical direction. The height of the entrance slit was larger than $1 \mathrm{~cm}$; consequently, the flight-out-of-view effects were considered to be negligible. As a test, we also measured the level of Os I at $28331.736 \mathrm{~cm}^{-1}$, and the value obtained, $230 \pm 20 \mathrm{~ns}$, agrees well with the results by Kwiatkowski et al. (1984) and Ivarsson et al. (2003).

Collisional quenching and radiation trapping effects were considered negligible since the background pressure in the 


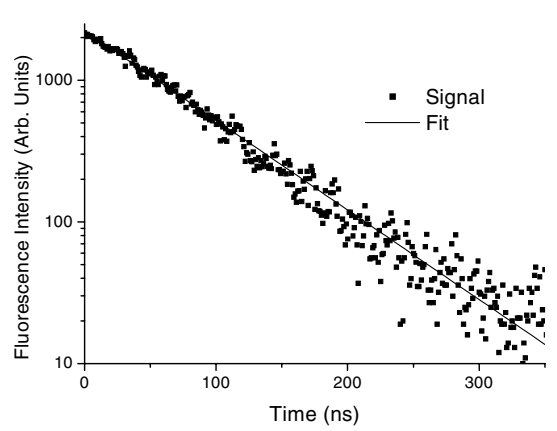

Fig. 2. A typical Os II experimental decay curve with an exponential fit. The lifetime for this level, situated at $39389.49 \mathrm{~cm}^{-1}$, is 66(6) ns.

vacuum chamber was very low, and since consistent lifetime values were obtained when the detected fluorescence intensity was varied by a factor of 10 when changing the delay time between the ablation and the excitation pulses $(\mathrm{Xu}$ et al. 2003a,b,c,d). This delay was between 3 and $10 \mu$ s for the Os I measurements and between 2 and $5 \mu$ s for Os II. The difference in delay times between Os I and Os II is explained by the fact that the atoms have lower speeds than the ions. In addition, Zeeman quantum beats were also considered by adding or removing a static magnetic field of about 100 Gauss. This field was provided by a pair of Helmholtz coils. No effect was observed. In order to obtain a sufficiently smooth curve for evaluating the radiative lifetimes, each decay curve was obtained by averaging fluorescence photons from 1000 pulses. To ensure that saturation effects in the excitation were eliminated, the fluorescence signals were recorded with different neutral density filters inserted in the exciting laser light path. For each level measured, the final lifetime value was obtained from at least 8 separate measurements under different experimental conditions. The error bars reported in Tables 3 and 4 represent the statistical uncertainties.

\section{Calculations in Os I}

The ground state of Os I, as established by Albertson (1934), is $5 d^{6} 6 s^{2}{ }^{5} D_{4}$. The configuration $5 d^{6} 6 s^{2}$ is strongly interacting with $5 d^{7} 6 s$ and $5 d^{8}$ even if no levels of this last configuration could be found in the early analyses. In the odd parity system, most of the levels identified belong to the configurations $5 d^{6} 6 s 6 p, 5 d^{5} 6 s^{2} 6 p$ and $5 d^{7} 6 p$ while higher even states belong to $5 d^{6} 6 s 7 s, 5 d^{5} 6 s^{2} 7 s$ and $5 d^{6} 6 s 6 d$ configurations. In Os II, the low lying levels belong to the configurations $5 \mathrm{~d}^{6} 6 \mathrm{~s}$ (ground configuration), $5 \mathrm{~d}^{5} 6 \mathrm{~s}^{2}$ and $5 \mathrm{~d}^{7}$ (even parity) and $5 \mathrm{~d}^{5} 6 \mathrm{~s} 6 \mathrm{p}$ and $5 d^{6} 6 p$ (odd parity). The levels of Os I and Os II, used in the least-squares fit procedure of the present work (see further), have been taken from Van Kleef \& Klikenberg (1961). The ionization potential of Os I was chosen equal to $68058.9 \pm$ $1.6 \mathrm{~cm}^{-1}$ (Colarusso et al. 1997).

Calculations of BFs in Os I were carried out using the pseudo-relativistic Hartree-Fock (HFR) approach of Cowan (1981) modified for taking core-polarization effects into account by means of the addition of a core-polarization potential and a correction to the dipole operator $(\mathrm{HFR}+\mathrm{CP})$

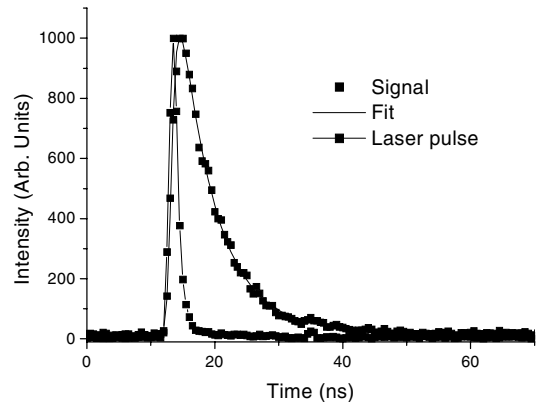

Fig. 3. Detected time-resolved fluorescence signal from the level at $46776.29 \mathrm{~cm}^{-1}$ in Os I and the recorded excitation laser pulse. The convolution procedure gives a lifetime of $4.8(0.3) \mathrm{ns}$.

as described in many previous papers (see e.g. Quinet et al. 1999). Configuration interaction was explicitly retained among $5 d^{6} 6 s^{2}, 5 d^{6} 6 p^{2}, 5 d^{6} 6 s 7 s, 5 d^{6} 6 s 6 d, 5 d^{7} 6 s, 5 d^{7} 7 s, 5 d^{7} 6 d$, $5 d^{5} 6 s^{2} 7 s, 5 d^{5} 6 s^{2} 6 d$ and $5 d^{8}$ for the even parity and $5 d^{6} 6 s 6 p$, $5 d^{6} 6 s 7 p, 5 d^{6} 6 s 5 f, 5 d^{7} 6 p, 5 d^{7} 7 p, 5 d^{7} 5 f$ and $5 d^{5} 6 s^{2} 6 p$ for the odd parity. Core-polarization effects were considered by using a dipole polarizability, $\alpha_{\mathrm{d}}$, equal to $6.55 \mathrm{au}$, as published by Fraga et al. (1976) for the Ta-like Os IV ionic core while the value of the cut-off radius, $r_{\mathrm{c}}$, was chosen to be equal to $1.74 \mathrm{au}$ which corresponds to the expected $\langle r\rangle$ value of the outermost core orbital, i.e. $5 \mathrm{~d}$, as calculated with the Cowan's code.

The scaling factors of the $F^{k}, G^{k}$ and $R^{k}$ integrals were chosen to be equal to 0.80 while the spin-orbit parameters, $\zeta_{n l}$, were left at their ab initio values according to a well established procedure (see e.g. Biémont et al. 2002, 2003; Xu et al. 2003a,b,c,d). The HFR + CP method was then combined with a least-squares optimization routine minimizing the discrepancies between calculated and experimental energy levels published by Van Kleef \& Klinkenberg (1961). Only the 46 evenparity levels below $32000 \mathrm{~cm}^{-1}$ and the 95 odd-parity levels for which a spectroscopic designation is given by the latter authors were included in the fitting process. These levels belong to the $5 d^{6} 6 s^{2}, 5 d^{7} 6 s, 5 d^{6} 6 s 6 p$ and $5 d^{7} 6 p$ configurations. The mean deviations of the fits were found to be equal to $78 \mathrm{~cm}^{-1}$ and $230 \mathrm{~cm}^{-1}$ for even and odd parities, respectively.

The theoretical lifetime values (both HFR and HFR + $\mathrm{CP}$ results) are compared in Table 3 with the experimental results. It is seen that some levels are very sensitive to CP effects. If we except the levels at 33124.48 and $36826.39 \mathrm{~cm}^{-1}$, the agreement between HFR+CP lifetimes and LIF measurements ranges from 2 to $38 \%$ which is quite satisfactory in view of the complexity of the configurations involved.

Radiative transition probabilities obtained for Os I lines are reported in Table 5. These gA-values were deduced from the combination of BFs calculated using the $\mathrm{HFR}+\mathrm{CP}$ method, as described above, and the experimental lifetimes measured in the present work and reported in Table 3 if we except the levels situated at $23462.90 \mathrm{~cm}^{-1}$ and $29381.65 \mathrm{~cm}^{-1}$ for which the lifetimes published by Kwiatkowski et al. (1984), i.e. $\tau=800 \pm$ $70 \mathrm{~ns}$ and $\tau=99 \pm 8 \mathrm{~ns}$, respectively, were used and the levels situated at $30279.95 \mathrm{~cm}^{-1}$ and $32684.61 \mathrm{~cm}^{-1}$ for which the measurements of Ivarsson et al. (2003), i.e. $\tau=93 \pm 7 \mathrm{~ns}$ and $\tau=28 \pm 2 \mathrm{~ns}$, were considered. 


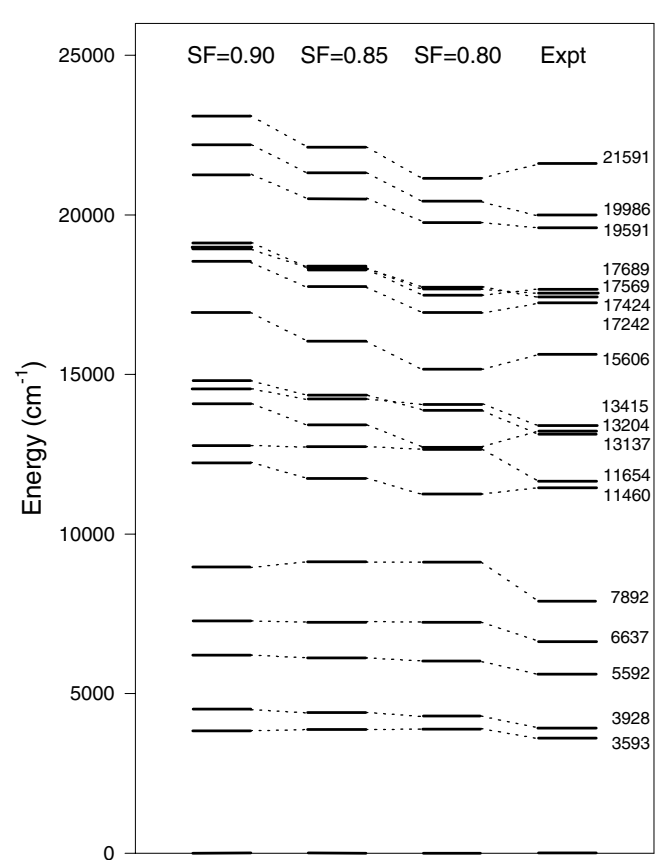

Fig. 4. Comparison between experimental and theoretical even energy levels in Os II. The calculations have been performed with 3 scaling factors $(\mathrm{SF}=0.80,0.85$ and 0.90$)$.

\section{Transition probabilities in Os II}

For Os II, an approach similar to that adopted in Os I was considered. In the HFR calculations, configuration interaction was explicitly retained among $5 d^{6} 6 s, 5 d^{6} 7 \mathrm{~s}, 5 d^{6} 6 d, 5 d^{5} 6 s^{2}, 5 d^{5} 6 p^{2}$, $5 d^{5} 6 s 6 d$ and $5 d^{7}$ for the even parity and $5 d^{6} 6 p, 5 d^{6} 7 p, 5 d^{6} 5 f$, $5 d^{5} 6 s 6 p$ and $5 d^{5} 6 s 5 f$ for the odd parity. Core-polarization effects were considered by using the same dipole polarizability value, $\alpha_{\mathrm{d}}$, and cut-off radius, $r_{\mathrm{c}}$, as in Os I. Only 22 and 21 levels of Os II belonging to the even and odd parities, respectively, were deduced experimentally by Van Kleef \& Klinkenberg (1961). Among these, 17 and 16, respectively, have been identified as belonging to the $5 d^{6} 6 s, 5 d^{5} 6 s^{2}, 5 d^{7}$ and $5 d^{6} 6 p, 5 d^{5} 6 s 6 p$ configurations indicating a rather poor knowledge of this ion since these configurations give normally rise to a total of 119 and 597 possible levels, respectively. Consequently, a reasonable semi-empirical fit of the radial integrals could not be achieved and only the average energies could be adjusted in these configurations.

To overcome this problem and in order to reproduce the experimental spectrum as well as possible, different scaling factors (SF) of the electrostatic parameters $F^{k}, G^{k}$ and $R^{k}$ integrals were tested and it was found that the best value, i.e. the one giving rise to the best agreement between calculated and experimental levels in both parities, was 0.80 . In fact, when using $\mathrm{SF}=0.90,0.85,0.80$ and 0.75 , we found that the mean deviations between theory and experiment were equal to 1107 , 665,445 and $692 \mathrm{~cm}^{-1}$ for the even parity levels and 2443, 1293,496 and $1385 \mathrm{~cm}^{-1}$ for the odd parity levels, respectively. This is illustrated in Figs. 4 and 5 where theoretical levels obtained using different scaling factors are compared to experimental values for both parities. It was also verified that the use of $\mathrm{SF}=0.80$ gave rise to a good agreement between the

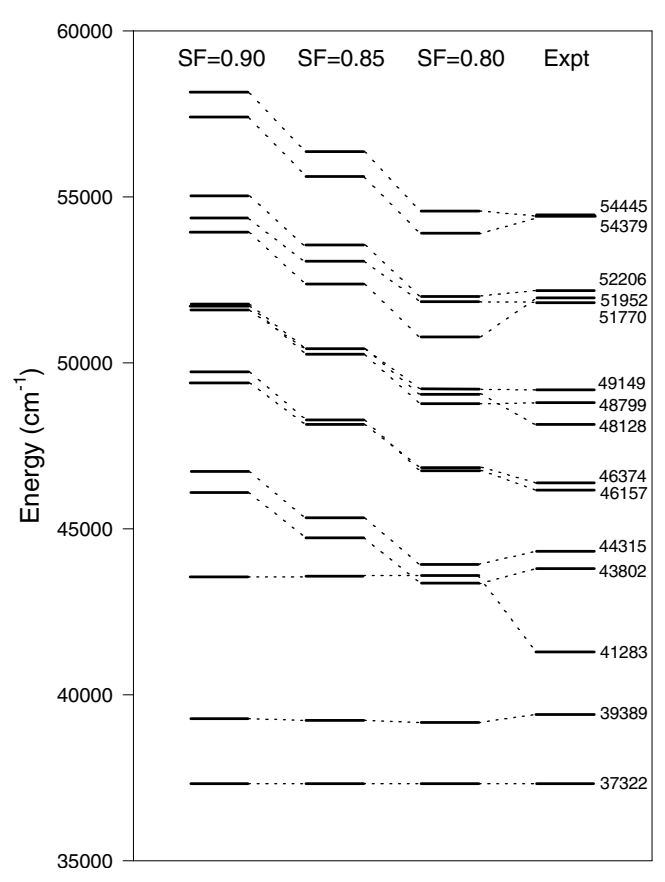

Fig. 5. Same as Fig. 4 for odd levels of Os II.

theoretical Landé g-factors and the observed values published by Van Kleef \& Klinkenberg (1961).

Experimental and theoretical lifetimes are compared in Table 4. It can be seen that a very good agreement is found if we except the level at $39389.49 \mathrm{~cm}^{-1}$ for which the theoretical value is three times longer than the experimental measurements. This can be explained by the fact that several transitions depopulating this particular level are affected by severe cancellation effects in the calculations. Indeed, for these lines, the cancellation factor, CF, as defined by Cowan (1981) takes very small values $(\mathrm{CF}<0.01)$ indicating that destructive interference effects, due to strong basis functions mixings, are present in the calculations of line strengths. Theoretical branching fractions and transition probabilities as obtained in the present work are listed in Table 6 where they are compared with the few experimental values published by Ivarsson et al. (2004). These latter authors determined $27 \mathrm{gA}$-values by combining radiative lifetimes measured using the LIF technique with BFs determined from Fourier transform spectrometer line intensities.

\section{Osmium in the sun and in stars}

Several Os II ultraviolet lines were detected in the prototypical HgMn star $\chi$ Lupi (Leckrone et al. 1999; Ivarsson et al. 2004), as already mentioned in Sect. 1 . The abundance analysis of $\chi$ Lupi by Ivarsson et al. (2004) relied on new measurements of transition probabilities, which were used as well to constrain the calculations performed in the present work (Table 6). The Os abundances derived in $\chi$ Lupi thus made use of the latest $\log g f$ values available, so that there is no need to discuss them further here.

Table 7 lists all the Os I lines which have been used so far to derive the solar Os abundance as well as Os abundances 
Table 7. Os I lines previously observed in the Sun and the stars. Lines between parentheses turn out to be unsuitable for Os abundance determination, because they are either too weak or heavily blended in the sun or in metal-poor stars.

\begin{tabular}{|c|c|c|c|c|c|c|}
\hline \multirow[t]{2}{*}{ 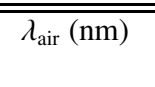 } & \multicolumn{2}{|c|}{$\overline{\log g f}$} & & \multirow[t]{2}{*}{$\overline{\text { Object }}$} & \multirow[t]{2}{*}{ 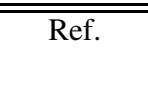 } & \multirow[t]{2}{*}{$\overline{\text { Remark }}$} \\
\hline & This work & Previous & Ref. & & & \\
\hline 283.8622 & -0.02 & 0.11 & $a, b$ & Metal-poor stars & $(1,2)$ & \\
\hline 301.8036 & -0.79 & -0.72 & $\mathrm{a}, \mathrm{b}$ & $\begin{array}{l}\text { Metal-poor stars } \\
\text { Sun }\end{array}$ & (2) & $\begin{array}{l}\text { In the wing of a strong line } \\
\text { In the wing of the strong lines Fe I } 302.0491 \text {, } \\
302.0639 \text { and } 302.1073 \mathrm{~nm} \text {. Unidentified fea- } \\
\text { ture at } 301.8025 \mathrm{~nm}\end{array}$ \\
\hline \multirow[t]{2}{*}{305.8660} & -0.41 & $-0.43,-0.45$ & $\mathrm{~b}, \mathrm{c}$ & Metal-poor stars & $(1,2,5,6)$ & $\begin{array}{l}\text { In wing of stronger unidentified line at } \\
305.8706 \mathrm{~nm}\end{array}$ \\
\hline & & & & Sun & (3) & $\begin{array}{l}\text { In wing of the strong Fe I } 305.9054 \mathrm{~nm} \text { and an } \\
\text { unidentified line at } 305.8706 \mathrm{~nm}\end{array}$ \\
\hline \multirow[t]{2}{*}{326.7945} & -1.09 & -1.08 & $\mathrm{~b}$ & Metal-poor stars & $(2,5,6)$ & \\
\hline & & & & Sun & $(3,8)$ & $\begin{array}{l}\text { Blend with too strong } \mathrm{Fe} \text { I } 326.7992 \mathrm{~nm} \\
\text { (Fig. 6a) }\end{array}$ \\
\hline 326.9204 & -1.00 & -1.070 & $\mathrm{c}$ & Metal-poor stars & (5) & \\
\hline 330.1559 & -0.74 & $-0.75,-0.743$ & $\mathrm{~b}, \mathrm{c}$ & $\begin{array}{l}\text { Sun } \\
\text { Metal-poor stars } \\
\text { Sun }\end{array}$ & $\begin{array}{l}(2,5,6,8) \\
\quad(3,8)\end{array}$ & $\begin{array}{l}\text { Very weak, in the wing of Fe I } 426.9232 \mathrm{~nm} \\
\text { (Fig. 7) } \\
\text { Clean line (Fig. 6b) }\end{array}$ \\
\hline 350.4662 & - & -1.636 & $\mathrm{c}$ & $\begin{array}{l}\text { Metal-poor stars } \\
\text { Sun }\end{array}$ & (5) & Strong unidentified features (e.g. $350.468 \mathrm{~nm}$ ) \\
\hline 352.8602 & - & -1.740 & $\mathrm{c}$ & $\begin{array}{l}\text { Metal-poor stars } \\
\text { Sun }\end{array}$ & $(5,6)$ & Bad fit of the synthetic spectrum \\
\hline$(375.2524)$ & -0.98 & -0.99 & $\mathrm{~b}$ & Sun & (3) & $\begin{array}{l}\text { Nd II at } 375.249 \text { is the principal contributor to } \\
\text { the feature }\end{array}$ \\
\hline$(397.7231)$ & -1.94 & $-1.59,-1.77$ & $\mathrm{~b}, \mathrm{c}$ & Sun & (3) & $\begin{array}{l}\text { Very weak solar line }\left(W_{\lambda}=0.7 \mathrm{~m} \AA\right) \text {, blend with } \\
\text { Fe I } 397.7166 \mathrm{~nm} \text { and Co I } 397.7177 \mathrm{~nm}\end{array}$ \\
\hline (409.1817) & - & -1.66 & $\mathrm{~b}$ & Sun & (3) & Very weak solar line $\left(W_{\lambda}=0.6 \mathrm{~m} \AA\right)$ \\
\hline$(413.5774)$ & -1.24 & $-1.26,-1.35$ & $\mathrm{a}, \mathrm{b}, \mathrm{c}$ & Metal-poor stars & $(4,5,7)$ & $\begin{array}{l}\text { Blend with Zr I (413.5656), Fe I ( } 413.5755), \mathrm{Sm} \\
\text { II (413.5142); this line yields a } 0.4 \text { dex too high } \\
\text { Os abundance in CS 31082-001 (Ivarsson et al. } \\
2003 \text { ) } \\
\text { idem }\end{array}$ \\
\hline \multirow[t]{2}{*}{426.0848} & -1.43 & $-1.44,-1.47$ & $a, b, c$ & Metal-poor stars & $(4,5,7)$ & \\
\hline & & & & Sun & & $\begin{array}{l}\text { In the wing of FeI (426.0486) and an unidenti- } \\
\text { fied line }\end{array}$ \\
\hline \multirow[t]{2}{*}{442.0468} & -1.20 & -1.53 & $\mathrm{~b}$ & Metal-poor stars & (4) & $\begin{array}{l}\text { Very high resolution is necessary to disentan- } \\
\text { gle from SmII ( } 442.0526) \text {; this line yields a } 0.3 \\
\text { dex too high Os abundance in CS } 31082-001 \\
\text { (Ivarsson et al. 2003) }\end{array}$ \\
\hline & & & & Sun & $(3,8)$ & $\begin{array}{l}\text { Separation from SmII (442.0526) is sufficient to } \\
\text { constrain the abundance (Fig. 6c) }\end{array}$ \\
\hline$(455.0410)$ & - & -0.71 & $\mathrm{~b}$ & Sun & (3) & Very weak solar line $\left(W_{\lambda}=0.4 \mathrm{~m} \AA\right)$ \\
\hline$(463.1828)$ & - & -1.19 & $\mathrm{~b}$ & Sun & (3) & Very weak solar line $\left(W_{\lambda}=0.1 \mathrm{~m} \AA\right)$ \\
\hline
\end{tabular}

a: Corliss \& Bozman (1962) b: Kwiatkowski et al. (1984) c: Ivarsson et al. (2003).

(1) Sneden et al. (1998); (2) Cowan et al. (2002); (3) Kwiatkowski et al. (1984); (4) Sneden et al. (1996); (5) Ivarsson et al. (2003); (6) Sneden et al. (2003); (7) Hill et al. (2002); (8) This work.

in very metal-poor stars enriched in heavy elements (Sneden et al. 1996, 1998, 2003; Cowan et al. 2002; Hill et al. 2002; Ivarsson et al. 2003). Table 7 also compares the old and new $\log g f$ values. Since the equivalent width is proportional to $g f \times \varepsilon_{\mathrm{Os}}$, as a gross approximation a change of oscillator strength of $\Delta \log g f$ will result in a logarithmic abundance variation $\Delta \log \varepsilon_{\mathrm{Os}}=-\Delta \log g f$ where $\log \varepsilon_{\mathrm{Os}}$ is expressed on the usual logarithmic scale relative to hydrogen $\left(\log \varepsilon_{\mathrm{Os}}=\right.$ $\left.\log \left[N_{\mathrm{Os}} / N_{\mathrm{H}}\right]+12.00\right)$.
For all but one line listed in Table 7 , the $\log g f$ values changed by less than 0.1 dex, so that the impact on the stellar abundances may be considered negligible. These lines are indeed the strongest ones in the considered wavelength range and it is expected that their $\log g f$ should be reliable. The Os I line at $442.0468 \mathrm{~nm}$ is an exception, since the $\log g f$ changed by +0.33 dex. However Table 5 shows that the calculation of the branching fraction is in good agreement (2\%) with the experimental measurements. Moreover, considering the r-process 
Table 8. Lines used to derive the solar Os abundance. Abundances are derived using either the Holweger-Müller or MARCS models.

\begin{tabular}{llcc}
\hline \hline Wavelength & \multirow{2}{*}{$\begin{array}{l}\text { log } g f^{*} \\
(\mathrm{~nm})\end{array}$} & & \multicolumn{2}{c}{$\log \varepsilon_{\mathrm{Os}}$} \\
\cline { 3 - 4 } & & $\mathrm{H}-\mathrm{M}$ & MARCS \\
326.7945 & -1.09 & 1.40 & 1.30 \\
330.1559 & -0.74 & 1.30 & 1.25 \\
442.0468 & -1.20 & 1.15 & 1.10 \\
& & 1.28 & 1.22 \\
Average & & \multicolumn{3}{c}{1.25} \\
Global average & & & \\
\hline
\end{tabular}

* Deduced from semi-empirical gA-values of Table 5. Uncertainties are estimated to be about $20-25 \%$.

enriched star CS 31082-001, the new $\log g f$ value $(-1.20$ instead of -1.53 ) nicely helps to reconcile the abundance derived from this line $\left(\log \varepsilon_{\mathrm{Os}}=0.5\right.$ with the former $\log g f$, Ivarsson et al. 2003) with the mean abundance derived from seven other Os I lines $\left(\log \varepsilon_{\mathrm{Os}}=0.2\right.$, Ivarsson et al. 2003).

\subsection{A new solar abundance for osmium}

Os I has been observed in the solar photosphere: an abundance value $\log \varepsilon_{\mathrm{Os}}=0.70$ was proposed by Jacoby \& Aller (1976) on the basis of the oscillator strengths available at that time (Corliss \& Bozman 1962). Using spectral synthesis, these authors retained for their analysis three different lines (at 305.8706, 330.1579 and $442.0460 \mathrm{~nm}$ ). This abundance value was considerably revised by Kwiatkowski et al. (1984) using their lifetime measurements and improved solar observations. Their abundance value, $\log \varepsilon_{\mathrm{Os}}=1.45 \pm 0.10$, was found to be in agreement with the meteoritic abundance as deduced by Anders \& Ebihara (1982).

We have reconsidered the problem of the solar abundance using the new atomic data. The Turbospectrum package (Alvarez \& Plez 1998) has been used to compute synthetic spectra, using either the Holweger-Müller solar model or a solar model extracted from the MARCS grid (Gustafsson et al. 2002). The partition functions are taken from Irwin (1981). The isotopic structure as well as the hyperfine structure of ${ }^{189} \mathrm{Os}$ have been taken into account, using data from Blaise \& Wyart (1989) and Kröger et al. (2002). Among all the lines examined, only three (at 326.7945, 330.1559 and $442.0468 \mathrm{~nm}$ ) were retained for the final analysis. Some of the very faint lines, considered previously by Kwiatkowski et al. (1984), were discarded, first because of their faintness (equivalent widths $<$ $2 \mathrm{m \AA}$ ) and sensitivity to blends in the solar spectrum (see Table 7) and second, because they are more likely to be affected by large uncertainties on their $\log g f$ values. The final Os abundance value, based on the three lines mentioned in Table 8 and averaged between the Holweger-Müller and MARCS results, is $\log \varepsilon_{\mathrm{Os}}=1.25 \pm 0.11$, where the uncertainty corresponds to one standard deviation. The hyperfine and isotopic structure of the lines have no measurable impact on that value.
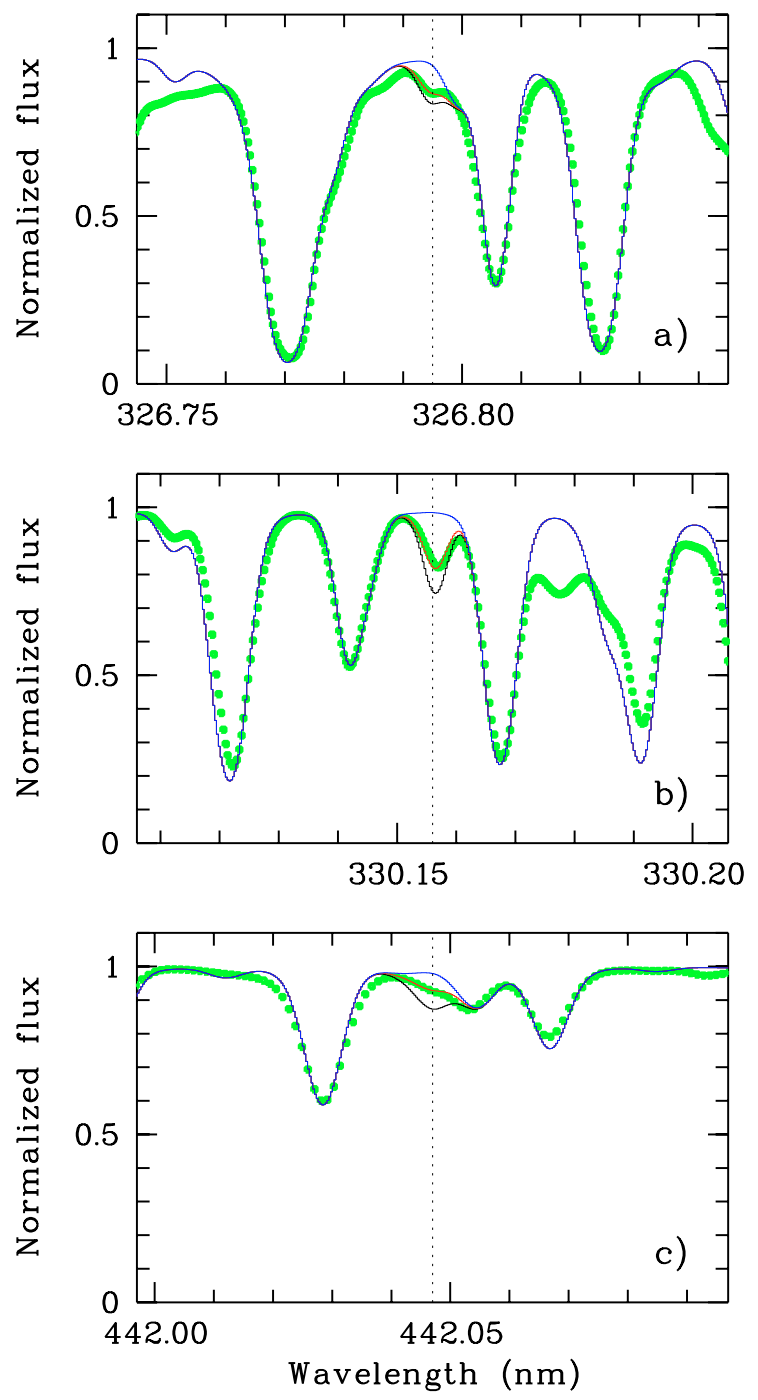

Fig. 6. Osmium lines at $326.7945,330.1559$ and $442.0468 \mathrm{~nm}$ (as indicated by the dotted vertical lines). The thick dotted line is the observed solar spectrum, and the 3 thin lines correspond (from top to bottom in each subfigure) to spectral synthesis (i) with no osmium; (ii) with the Os abundance as listed in Table 8; and (iii) with the former standard solar Os abundance $\log \varepsilon_{\mathrm{Os}}=1.45$. These spectral synthesis have been produced with the MARCS solar model taking the isotopic and hyperfine structures into account.

We now discuss these three lines separately:

a) $\lambda 326.7945 \mathrm{~nm}$ (Fig. 6a): an artificial line has been introduced to fit the nearby line at $326.8057 \mathrm{~nm}$. Moreover, this osmium line is blended with a Fe I at $326.7992 \mathrm{~nm}(\log g f=$ -2.751, VALD2). The $\log g f$ of this Fe I line has been adapted to improve the fit $(\log g f=-3.8)$. The osmium line is then fitted with $\log \varepsilon_{\mathrm{Os}}=1.30$ with the MARCS solar model and $\log \varepsilon_{\mathrm{Os}}=1.40$ with the Holweger-Müller model. There is some veiling opacity in this region, which is unaccounted for, and may be responsible for the somewhat larger Os abundance. This line is the less secure of the three osmium lines used to derive the solar abundance.

b) $\lambda 330.1559 \mathrm{~nm}$ (Fig. 6b): this is the cleanest and thus most reliable line. An artificial line has been introduced to fit the nearby line at $330.1418 \mathrm{~nm}$. The osmium line is 
well-fitted with $\log \varepsilon_{\mathrm{Os}}=1.25$ with the MARCS solar model and $\log \varepsilon_{\mathrm{Os}}=1.30$ with the Holweger-Müller model.

c) $\lambda 442.0468 \mathrm{~nm}$ (Fig. 6c): this line is blended by Nd II and Sm II lines (Moore et al. 1966; VALD-2 (Kupka et al. 1999); see also the D.R.E.A.M. database which is accessible on the following web site http://www. umh.ac.be/ astro/dream. shtml). The oscillator strength of the Sm II (442.0524 nm) line, as listed in VALD-2, is too strong $(\log g f=-0.383)$. The $\log g f$ of this $\mathrm{Sm}$ line was adapted in order to fit the rightmost side of the blend $(\log g f=-1.983)$. The Os line is well-fitted with $\log \varepsilon_{\mathrm{Os}}=1.10$ with the MARCS solar model and $\log \varepsilon_{\mathrm{Os}}=1.15$ with the Holweger-Müller model. The $442.0516 \mathrm{Nd}$ II line has very little impact. Thanks to the separation between the Os and the Sm lines, the Os abundance is well-constrained; in particular, the osmium abundance does not change if it is determined before the Sm line is adjusted. An artificial line is introduced at $442.0285 \mathrm{~nm}$.

For meteorites, Asplund et al. (2005) give $\log \varepsilon_{\mathrm{Os}}=1.34 \pm$ 0.03 , corresponding to a slight rescaling of the Lodders (2003) value. Our new determination $\left(\log \varepsilon_{\mathrm{Os}}=1.25 \pm 0.11\right)$ is thus slightly closer to the meteoritic result than the value reported by Kwiatkowski et al. (1984).

The choice of the lines selected to derive the solar abundance is critical. The inclusion of the very faint lines (equivalent widths $<2 \mathrm{~m} \AA$ ), as done by Kwiatkowski et al. (1984), clearly shifts the mean abundance to higher values. These lines were however excluded for the reasons stated above.

\subsection{Osmium in stars}

The CH star HD 187861 was observed on April 2, 2002, on the high-resolution UVES spectrograph of the Paranal ESO observatory in Chile. Figure 7 presents the high-resolution spectrum of this star around $330.1559 \mathrm{~nm}$. Although the spectrum is a bit noisy, the osmium line is clearly visible. Stellar parameters have been determined for this star (Masseron et al., in prep.), dedicated MARCS model atmospheres have been built and the Turbospectrum package (Alvarez \& Plez 1998) has been used to compute synthetic spectra. The osmium abundance determined from Fig. 7 is $\log \varepsilon_{\mathrm{Os}}=0.55$ for this star of metallicity $[\mathrm{Fe} / \mathrm{H}]=-2.3$, which implies $[\mathrm{Os} / \mathrm{Fe}]=1.6 \mathrm{dex}$. Considering the fact that osmium is generally believed to trace the r-process of nucleosynthesis, this large overabundance is surprising in a CH star where s-process element overabundances are usually reported. An on-going abundance analysis indeed reveals that HD 187861 exhibits s-process element overabundances similar to the level reported for osmium, thus making it another example of the rare class of s-r-enriched stars (e.g. Cohen et al. 2003).

Acknowledgements. This work was financially supported by the Swedish Natural Science Research Council and by the EU-TMR access to Large-Scale Infrastructure Programme (contract HPRI-CT-1999-00041). Financial support from the Belgian

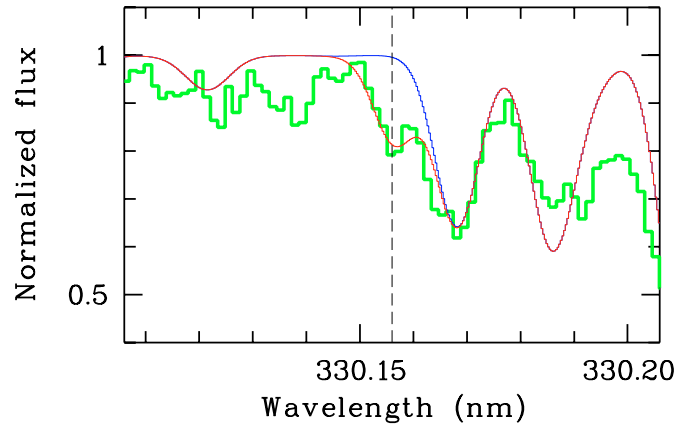

Fig. 7. The Os I $330.1559 \mathrm{~nm}$ line in a carbon-rich metal-poor star. The thick line corresponds to the observed spectrum of the $\mathrm{CH}$ star HD 187861. The thin lines correspond to spectral synthesis using a dedicated MARCS model without osmium, and with an osmium abundance of $\log \varepsilon_{\mathrm{Os}}=0.55$.

FNRS is acknowledged by four of us (E.B.,A.J., S.V. and P.Q) who are respectively Research Director, Senior Research Associate and Research Associates of this organization.

\section{References}

Albertson, W. 1934, Phys. Rev., 45, 394

Albertson, W. 1938, Phys. Rev., 53, 940

Alvarez, \& Plez 1998, A\&A, 330, 1109

Anders, E., \& Ebihara, M. 1982, Geochim. Cosmochim. Acta, 46, 2363

Asplund, M., Grevesse, N., \& Sauval, A. J. 2005, in Cosmic Abundances as Records of Stellar Evolution and Nucleosynthesis, ed. F. N. Bash, \& T. G. Barnes, ASP Conf. Ser., San Francisco, in press

Aufmuth, P., \& Wökber, E. 1985, Z. Phys., A321, 65

Biémont, E., Garnir, H. P., Quinet, P., Svanberg, S., \& Zhang, Z. G. 2002, Phys. Rev. A, 65, 052502 (1-7)

Biémont, E., Garnir, H. P., Litzén, U., et al. 2003, A\&A, 399, 343

Blaise, J. 1957, Thesis (Paris)

Blaise, J. 1958, Ann. Phys. (Paris), 3, 1019

Blaise, J., \& Wyart, J.-F. 1989, in Gmelin Handbook of Inorganic Chemistry, 8th ed., Suppl. Vol. A2, 170 (Berlin: Springer-Verlag)

Brandi, E., \& Jaschek, M. 1970, PASP, 82, 847

Büttgenbach, S., Dicke, R., \& Träber, F. 1979, Phys. Rev. A, 19, 1383

Cohen, J. G., Christlieb, N., Qian, Y.-Z., \& Wasserburg, G. J. 2003, ApJ, 588, 1082

Colarusso, P., Lebeault-Dorget, M.-A., \& Simard, B. 1997, Phys. Rev., 55,1526

Corliss, C. H., \& Bozman, W. R. 1962, Nat. Bur. Stand. Monograph 53 (US Department of Commerce, Washington DC)

Cowan, R. D. 1981, The Theory of Atomic Structure and Spectra (Berkeley, California, USA: Univ. of California Press)

Cowan, J. J., Sneden, C., Burles, S., et al. 2002, ApJ, 572, 861

Cowley, C. R. 1987, Obs., 107, 188

Davis, D. N. 1947, ApJ, 106, 28

Doidge, P. S. 1995, Spectrochim. Acta, Part B50, 209; 1996, 50, 1421; 1996, 51, 375

Fraga, S., Karwowski, J., \& Saxena, K. M. S. 1976, Handbook of Atomic Data (Amsterdam: Elsevier)

Gluck, G. 1965, Ann. Phys. (Paris), 10, 673 
Gluck, G. G., Bordarier, Y., Bauche, J., \& van Kleef, Th. A. M. 1964, Physica, 30, 2068

Gustafsson, B., Edvardsson, B., Eriksson, K., et al. 2002, in Stellar Atmosphere Modeling, ed. I. Hubeny, D. Mihalas, \& K. Werner, ASP Conf. Ser., 288, 331

Guthöhrlein, G., Kopfermann, H., Nöldeke, G., \& Steudel, A. 1961, Z. Phys., 165, 356

Guthöhrlein, G., Himmel, G., \& Steudel, A. 1969, J. Phys. Colloq. (Paris), 30, C1-66

Guthrie, B. N. G. 1969, Obs., 89, 224

Harrison, G. R. 1939, MIT Wavelength Tables (Wiley, New York)

Hill, V., Plez, B., Cayrel, R., et al. 2002, A\&A, 387, 560

Himmel, G. 1968, Z. Physik, 211, 68

Hines, A. P., \& Ross, J. S. 1962, Phys. Rev., 126, 2105

Irwin 1981, ApJ, 45, 621

Ivarsson, S., Andersen, J., Nordström, B., et al. 2003, A\&A, 409, 1141

Ivarsson, S., Wahlgren, G. M., Dai, Z., Lundberg, H., \& Leckrone, D. S. 2004, A\&A, 425, 353

Jacoby, G., \& Aller, L. H. 1976, Proc. Nat. Acad. Sci. USA, 73, 1382

Kawada, T. 1938, Proc. Phys. Math. Soc. Japan, 20, 653

Kwiatkowski, M., Zimmermann, P., Biémont, E., \& Grevesse, N. 1984, A\&A, 135, 59

Kröger, S., Basar, G., Baier, A., \& Guthörhlein, H. G. 2002, Phys. Scr., 65,56

Kupka, F., Piskunov, N. E., Ryabchikova, T. A., Stempels, H. C., \& Weiss, W. W. 1999, A\&AS, 138, 119 (VALD-2)

Leckrone, D. S., Proffitt, C. R., Wahlgren, G. M., Johansson, S. G., \& Brage, G. 1999, AJ, 117, 1454

Lodders, K. 2003, AJ, 591, 1220

Loeliger, H. R., \& Sarles, L. R. 1954, Phys. Rev., 95, 291

Meggers, W. F., \& Laporte, O. 1926, Phys. Rev., 28, 642

Meggers, W. F., Corliss, C. H., \& Scribner, B. F. 1975, NBS, Monograph 145 (US Department of Commerce, Washington DC)

Morton, D. C. 2000, ApJS, 130, 403

Morton, D. C. 2001, ApJS, 132, 411

Moore, C. E. 1958, Atomic Energy Levels, Vol. III, NBS, Monograph 467 (US Department of Commerce, Washington DC)
Moore, C. E., Minnaert, M. G. J., \& Houtgast, J. 1966, The Solar Spectrum 2935 to 8770 Second Revision of Rowland's Preliminary Table of Solar Spectrum Wavelengths, National Bureau of Standards Monograph 61, Washington DC

Murakawa, K. 1955, Phys. Rev., 98, 1285

Murakawa, K., \& Suwa, S. 1952, Phys. Rev., 87, 1048

Murakawa, K., \& Kamei, T. 1957, Phys. Rev., 105, 671

Nave, G., Johansson, S., Learner, R. C. M., Thorne, A. P., \& Brault, J. W. 1994, ApJS, 94, 221

Nöldeke, G., \& Saksena, G. D. 1962, Z. Phys., 166, 216

Nöldeke, G., Steudel, A., Wallach, K. E., \& Walther, H. 1962, Z. Physik, 170, 22

Quinet, P., Palmeri, P., Biémont, E., et al. 1999, MNRAS, 307, 934

Schiemann, S., Hogervorst, W., \& Ubachs, W. 1998, IEEE J. Quant. Electr., 34, 407

Sneden, C., Cowan, J. J., Burris, D. L., \& Truran, J. W. 1998, ApJ, 496, 235

Sneden, C., McWilliam, A., Preston, G. W., et al. 1996, ApJ, 467, 819

Sneden, C., Cowan, J. J., Lawler, J. E., et al. 2003, ApJ, 591, 936

Suwa, S. 1951, Phys. Rev., 83, 1258

Van den Bosch, J. C. 1955, Lund Univ. Årsskr. Proc. Rydberg Cent. Conf. At. Spectrosc., 80

Van den Bosch, J. C. \& Van Kleef, Th. A. M. 1956, unpublished (1956), quoted by Moore (1958)

Van Kleef, Th. A. M. 1960, Proc. Koninkl. Ned. Akad. Wetenschap., B63, 501

Van Kleef, Th. A. M., \& Klinkenberg, P. F. A. 1961, Physica, 27, 83

Wyart, J.-F. 1978, Phys. Scr., 18, 87

Xu, H. L., Svanberg, S., Quinet, P., Garnir, H. P., \& Biémont, E. 2003a, J. Phys. B, 36, 4773

Xu, H. L., Svanberg, S., Quinet, P., Garnir, H. P., \& Biémont, E. 2003b, J. Phys. B: At. Mol. Opt. Phys., 36, 4773

Xu, H. L., Svanberg, S., Cowan, R. D., et al. 2003c, MNRAS, 346, 433

Xu, H. L., Jiang, Z., Zhang, Z. G., et al. 2003d, J. Phys. B, 36, 1771

Xu, H. L., Person, A., Svanberg, S., et al. 2004, Phys. Rev. A, 70, 042508 
P. Quinet et al.: Transition probabilities and lifetimes in Os I and Os II, Online Material $p 1$

\section{Online Material}


P. Quinet et al.: Transition probabilities and lifetimes in Os I and Os II, Online Material $p 2$

Table 5. Branching fractions $(B F)$, transition probabilities $\left(g A\right.$ in $\left.10^{6} \mathrm{~s}^{-1}\right)$ and oscillator strengths $(\log g f)$ for transitions depopulating oddparity levels in Os I.

\begin{tabular}{|c|c|c|c|c|c|c|c|c|c|}
\hline \multirow{2}{*}{$\begin{array}{l}\text { Upper level }^{a} \\
\text { Energy }\left(\mathrm{cm}^{-1}\right)\end{array}$} & \multirow[t]{2}{*}{ 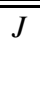 } & \multirow{2}{*}{$\begin{array}{r}\text { Lower level }^{a} \\
\text { Energy }\left(\mathrm{cm}^{-1}\right)\end{array}$} & \multirow[t]{2}{*}{$J$} & \multirow[t]{2}{*}{$\lambda(\mathrm{nm})^{b}$} & \multicolumn{2}{|c|}{ Experiment $^{c}$} & \multicolumn{3}{|c|}{ This work } \\
\hline & & & & & $B F$ & $g A$ & $B F^{d}$ & $g A^{e}$ & $\log g f^{e}$ \\
\hline 22615.69 & 4 & 0.00 & 4 & 442.0468 & 0.983 & & 0.963 & 21.69 & -1.20 \\
\hline \multirow[t]{3}{*}{$\tau=400(50)^{f} \mathrm{~ns}$} & & 4159.32 & 3 & 541.6678 & 0.001 & & 0.002 & 0.09 & -3.40 \\
\hline & & 5143.92 & 5 & 572.1931 & 0.012 & & 0.028 & 0.63 & -2.51 \\
\hline & & 11030.58 & 4 & 862.9399 & & & 0.006 & 0.18 & -2.70 \\
\hline 23462.90 & 5 & 0.00 & 4 & 426.0848 & 0.992 & 13.64 & 0.987 & 13.53 & -1.43 \\
\hline$\tau=800(70)^{g} \mathrm{~ns}$ & & 5143.92 & 5 & 545.7302 & & & 0.011 & 0.11 & -3.31 \\
\hline 28331.77 & 4 & 0.00 & 4 & 352.8598 & 0.287 & 9.72 & 0.362 & 14.13 & -1.58 \\
\hline \multirow[t]{3}{*}{$\tau=230(20)^{f} \mathrm{~ns}$} & & 4159.32 & 3 & 413.5774 & 0.515 & 17.46 & 0.568 & 22.23 & -1.24 \\
\hline & & 5143.92 & 5 & 431.1391 & 0.195 & 6.57 & 0.045 & 1.80 & -2.30 \\
\hline & & 8742.83 & 4 & 510.3499 & 0.002 & 0.09 & 0.022 & 0.81 & -2.50 \\
\hline 28371.68 & 3 & 0.00 & 4 & 352.3634 & & & 0.255 & 4.55 & -2.07 \\
\hline \multirow[t]{9}{*}{$\tau=390(50)^{f} \mathrm{~ns}$} & & 2740.49 & 2 & 390.0391 & & & 0.377 & 6.79 & -1.81 \\
\hline & & 4159.32 & 3 & 412.8957 & & & 0.214 & 3.85 & -2.01 \\
\hline & & 10165.98 & 2 & 549.1259 & & & 0.009 & 0.14 & -3.20 \\
\hline & & 11030.58 & 4 & 576.5048 & & & 0.020 & 0.35 & -2.76 \\
\hline & & 11378.00 & 3 & 588.2910 & & & 0.034 & 0.63 & -2.48 \\
\hline & & 13364.83 & 2 & 666.1784 & & & 0.016 & 0.28 & -2.73 \\
\hline & & 14091.37 & 3 & 700.0718 & & & 0.005 & 0.07 & -3.29 \\
\hline & & 15222.57 & 2 & 760.2984 & & & 0.059 & 1.05 & -2.04 \\
\hline & & 15390.76 & 3 & 770.1494 & & & 0.007 & 0.14 & -2.90 \\
\hline 29381.65 & 3 & 0.00 & 4 & 340.2508 & & & 0.059 & 4.20 & -2.14 \\
\hline \multirow[t]{7}{*}{$\tau=99(8)^{g} \mathrm{~ns}$} & & 2740.49 & 2 & 375.2524 & & & 0.707 & 49.98 & -0.98 \\
\hline & & 4159.32 & 3 & 396.3619 & & & 0.149 & 10.50 & -1.61 \\
\hline & & 10165.98 & 2 & 520.2637 & & & 0.067 & 4.76 & -1.71 \\
\hline & & 13364.83 & 2 & 624.1710 & & & 0.001 & 0.07 & -3.39 \\
\hline & & 14091.37 & 3 & 653.8296 & & & 0.004 & 0.28 & -2.75 \\
\hline & & 15222.57 & 2 & 706.0659 & & & 0.002 & 0.14 & -2.98 \\
\hline & & 15390.76 & 3 & 714.5538 & & & 0.008 & 0.56 & -2.37 \\
\hline 30279.95 & 5 & 0.00 & 4 & 330.1565 & 0.935 & 110.55 & 0.950 & 112.31 & -0.74 \\
\hline \multirow[t]{3}{*}{$\tau=93(7)^{h} \mathrm{~ns}$} & & 5143.92 & 5 & 397.7228 & 0.061 & 7.26 & 0.041 & 4.84 & -1.94 \\
\hline & & 8742.83 & 4 & 464.1846 & 0.003 & 0.33 & 0.002 & 0.22 & -3.15 \\
\hline & & 11030.58 & 4 & & & & 0.004 & 0.44 & -2.75 \\
\hline 30591.45 & 4 & 0.00 & 4 & 326.7945 & & & 0.554 & 50.85 & -1.09 \\
\hline \multirow[t]{5}{*}{$\tau=98(8)^{f} \mathrm{~ns}$} & & 4159.32 & 3 & 378.2200 & & & 0.427 & 39.15 & -1.08 \\
\hline & & 8742.83 & 4 & 457.5666 & & & 0.001 & 0.09 & -3.55 \\
\hline & & 11030.58 & 4 & 511.0823 & & & 0.007 & 0.63 & -2.61 \\
\hline & & 11378.00 & 3 & 520.3238 & & & 0.002 & 0.18 & -3.14 \\
\hline & & 15390.76 & 3 & 657.6832 & & & 0.007 & 0.63 & -2.39 \\
\hline
\end{tabular}


Table 5. continued.

\begin{tabular}{|c|c|c|c|c|c|c|c|c|c|}
\hline \multirow{2}{*}{$\begin{array}{l}\text { Upper level }^{a} \\
\text { Energy }\left(\mathrm{cm}^{-1}\right)\end{array}$} & \multirow[t]{2}{*}{ 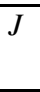 } & \multirow{2}{*}{$\begin{array}{r}\text { Lower level }{ }^{a} \\
\text { Energy }\left(\mathrm{cm}^{-1}\right)\end{array}$} & \multirow[t]{2}{*}{$\overline{J J}$} & \multirow[t]{2}{*}{$\bar{\lambda} \lambda(\mathrm{nm})^{b}$} & \multicolumn{2}{|c|}{ 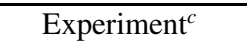 } & \multicolumn{3}{|c|}{ This work } \\
\hline & & & & & $B F$ & $g A$ & $B F^{d}$ & $g A^{e}$ & $\log g f^{e}$ \\
\hline 32684.61 & 4 & 0.00 & 4 & 305.8655 & 0.883 & 283.77 & 0.864 & 277.65 & -0.41 \\
\hline \multirow[t]{8}{*}{$\tau=28(2)^{h} \mathrm{~ns}$} & & 4159.32 & 3 & 350.4658 & 0.044 & 14.13 & 0.061 & 19.62 & -1.44 \\
\hline & & 5143.92 & 5 & 362.9956 & 0.002 & 0.72 & 0.014 & 4.50 & -2.05 \\
\hline & & 8742.83 & 4 & 417.5622 & 0.042 & 13.59 & 0.026 & 8.28 & -1.66 \\
\hline & & 11030.58 & 4 & 461.6785 & 0.017 & 5.40 & 0.016 & 5.13 & -1.78 \\
\hline & & 11378.00 & 3 & 469.2066 & 0.007 & 2.25 & 0.003 & 0.99 & -2.48 \\
\hline & & 14091.37 & 3 & 537.6804 & & & 0.004 & 1.26 & -2.26 \\
\hline & & 14338.99 & 5 & 544.9378 & & & 0.001 & 0.36 & -2.79 \\
\hline & & 15390.76 & 3 & 578.0799 & & & 0.007 & 2.25 & -1.95 \\
\hline \multirow{9}{*}{$\begin{array}{l}33124.48 \\
\tau=51(4)^{f} \mathrm{~ns}\end{array}$} & 3 & 0.00 & 4 & 301.8036 & & & 0.867 & 119.00 & -0.79 \\
\hline & & 2740.49 & 2 & 329.0259 & & & 0.020 & 2.73 & -2.35 \\
\hline & & 4159.32 & 3 & 345.1435 & & & 0.008 & 1.12 & -2.70 \\
\hline & & 8742.83 & 4 & 410.0288 & & & 0.007 & 0.98 & -2.61 \\
\hline & & 11030.58 & 4 & 452.4867 & & & 0.024 & 3.29 & -1.99 \\
\hline & & 11378.00 & 3 & 459.7157 & & & 0.001 & 0.14 & -3.35 \\
\hline & & 12774.38 & 2 & 491.2609 & & & 0.013 & 1.75 & -2.20 \\
\hline & & 13364.83 & 2 & 505.9408 & & & 0.001 & 0.14 & -3.27 \\
\hline & & 15222.57 & 2 & 558.4445 & & & 0.055 & 7.56 & -1.45 \\
\hline \multirow{3}{*}{$\begin{array}{l}34365.33 \\
\tau=25(2)^{f} \mathrm{~ns}\end{array}$} & 5 & 0.00 & 4 & 290.9057 & 0.978 & 448.47 & 0.988 & 434.72 & -0.26 \\
\hline & & 8742.83 & 4 & 390.1714 & 0.007 & 3.08 & 0.007 & 3.08 & -2.15 \\
\hline & & 11030.58 & 4 & 428.449 & 0.010 & 4.40 & 0.003 & 1.32 & -2.44 \\
\hline \multirow{9}{*}{$\begin{array}{l}34803.82 \\
\tau=58(5)^{f} \mathrm{~ns}\end{array}$} & 4 & 0.00 & 4 & 287.2405 & & & 0.133 & 20.61 & -1.59 \\
\hline & & 4159.32 & 3 & 326.2288 & & & 0.464 & 72.00 & -0.94 \\
\hline & & 5143.92 & 5 & 337.0587 & & & 0.310 & 48.06 & -1.09 \\
\hline & & 8742.83 & 4 & 383.6064 & & & 0.042 & 6.48 & -1.84 \\
\hline & & 11030.58 & 4 & 420.5225 & & & 0.003 & 0.45 & -2.92 \\
\hline & & 11378.00 & 3 & 426.7593 & & & 0.002 & 0.27 & -3.13 \\
\hline & & 14091.37 & 3 & 482.6665 & & & 0.006 & 0.90 & -2.50 \\
\hline & & 15390.76 & 3 & 514.9737 & & & 0.032 & 4.95 & -1.71 \\
\hline & & 18901.94 & 3 & 628.6826 & & & 0.004 & 0.63 & -2.43 \\
\hline \multirow{13}{*}{$\begin{array}{l}35615.92 \\
\tau=31(2)^{f} \mathrm{~ns}\end{array}$} & 3 & 0.00 & 4 & 280.6906 & & & 0.611 & 137.97 & -0.79 \\
\hline & & 2740.49 & 2 & 304.0900 & & & 0.252 & 56.91 & -1.10 \\
\hline & & 4159.32 & 3 & 317.8064 & & & 0.024 & 5.39 & -2.09 \\
\hline & & 8742.83 & 4 & 372.0136 & & & 0.052 & 11.76 & -1.61 \\
\hline & & 11030.58 & 4 & 406.6316 & & & 0.006 & 1.33 & -2.48 \\
\hline & & 11378.00 & 3 & 412.4603 & & & 0.016 & 3.64 & -2.03 \\
\hline & & 12774.38 & 2 & 437.6759 & & & 0.005 & 1.12 & -2.49 \\
\hline & & 13364.83 & 2 & 449.2901 & & & 0.006 & 1.33 & -2.39 \\
\hline & & 14848.05 & 4 & 481.3785 & & & 0.004 & 0.91 & -2.50 \\
\hline & & 15222.57 & 2 & 490.2190 & & & 0.016 & 3.64 & -1.88 \\
\hline & & 15390.76 & 3 & 494.2957 & & & 0.003 & 0.70 & -2.59 \\
\hline & & 18901.94 & 3 & 598.1358 & & & 0.001 & 0.21 & -2.95 \\
\hline & & 21303.36 & 2 & 698.4944 & & & 0.001 & 0.21 & -2.81 \\
\hline
\end{tabular}


Table 5. continued.

\begin{tabular}{|c|c|c|c|c|c|c|c|c|}
\hline \multirow{2}{*}{$\begin{array}{l}\text { Upper level } \\
\text { Energy }\left(\mathrm{cm}^{-1}\right)\end{array}$} & \multirow[t]{2}{*}{$\overline{J J}$} & \multirow{2}{*}{$\begin{array}{r}\text { Lower level }{ }^{a} \\
\text { Energy }\left(\mathrm{cm}^{-1}\right)\end{array}$} & \multirow[t]{2}{*}{$\overline{J J}$} & \multirow[t]{2}{*}{$\overline{\lambda \lambda(\mathrm{nm})^{b}}$} & Experiment ${ }^{c}$ & \multicolumn{3}{|c|}{ This work } \\
\hline & & & & & $B F$ & $B F^{d}$ & $g A^{e}$ & $\log g f^{e}$ \\
\hline 36826.39 & 4 & 0.00 & 4 & 271.4639 & & 0.422 & 84.42 & -1.03 \\
\hline \multirow[t]{11}{*}{$\tau=45(4)^{f} \mathrm{~ns}$} & & 4159.32 & 3 & 306.0297 & & 0.040 & 8.01 & -1.95 \\
\hline & & 5143.92 & 5 & 315.5406 & & 0.005 & 0.99 & -2.83 \\
\hline & & 8742.83 & 4 & 355.9785 & & 0.281 & 56.16 & -0.97 \\
\hline & & 11030.58 & 4 & 387.5500 & & 0.002 & 0.36 & -3.09 \\
\hline & & 11378.00 & 3 & 392.8409 & & 0.027 & 5.40 & -1.90 \\
\hline & & 14091.37 & 3 & 439.7265 & & 0.061 & 12.15 & -1.45 \\
\hline & & 14338.99 & 5 & 444.5687 & & 0.009 & 1.80 & -2.27 \\
\hline & & 14848.05 & 4 & 454.8659 & & 0.040 & 8.01 & -1.60 \\
\hline & & 15390.76 & 3 & 466.3824 & & 0.103 & 20.61 & -1.17 \\
\hline & & 19108.87 & 4 & 564.2565 & & 0.007 & 1.44 & -2.16 \\
\hline & & 21123.66 & 3 & 636.6559 & & 0.002 & 0.36 & -2.66 \\
\hline 37908.77 & 4 & 0.00 & 4 & 263.7126 & & 0.759 & 243.90 & -0.59 \\
\hline \multirow[t]{7}{*}{$\tau=28(2)^{f} \mathrm{~ns}$} & & 4159.32 & 3 & 296.2146 & & 0.124 & 39.87 & -1.28 \\
\hline & & 5143.92 & 5 & 305.1164 & & 0.016 & 5.13 & -2.14 \\
\hline & & 8742.83 & 4 & 342.7674 & & 0.077 & 24.75 & -1.36 \\
\hline & & 11378.00 & 3 & 376.8138 & & 0.004 & 1.26 & -2.57 \\
\hline & & 14091.37 & 3 & 419.7428 & & 0.007 & 2.25 & -2.23 \\
\hline & & 14848.05 & 4 & 433.5159 & & 0.007 & 2.25 & -2.20 \\
\hline & & 18901.94 & 3 & 525.9803 & & 0.002 & 0.63 & -2.58 \\
\hline 40361.92 & 4 & 0.00 & 4 & 247.6835 & & 0.127 & 134.46 & -0.91 \\
\hline \multirow[t]{5}{*}{$\tau=8.5(7)^{f} \mathrm{~ns}$} & & 4159.32 & 3 & 276.1417 & & 0.076 & 80.46 & -1.04 \\
\hline & & 5143.92 & 5 & 283.8622 & & 0.744 & 787.77 & -0.02 \\
\hline & & 8742.83 & 4 & 316.1731 & & 0.023 & 24.39 & -1.44 \\
\hline & & 11378.00 & 3 & 344.9201 & & 0.009 & 9.54 & -1.77 \\
\hline & & 14848.05 & 4 & 391.8327 & & 0.017 & 18.00 & -1.38 \\
\hline 46776.29 & 3 & 0.00 & 4 & 213.7161 & & 0.272 & 396.69 & -0.57 \\
\hline \multirow[t]{21}{*}{$\tau=4.8(3)^{f} \mathrm{~ns}$} & & 2740.49 & 2 & 227.0178 & & 0.294 & 428.75 & -0.48 \\
\hline & & 4159.32 & 3 & 234.5765 & & 0.023 & 33.53 & -1.56 \\
\hline & & 8742.83 & 4 & 262.8480 & & 0.025 & 36.47 & -1.42 \\
\hline & & 10165.98 & 2 & 273.0663 & & 0.021 & 30.59 & -1.47 \\
\hline & & 11030.58 & 4 & 279.6714 & & 0.090 & 131.25 & -0.81 \\
\hline & & 11378.00 & 3 & 282.4164 & & 0.034 & 49.56 & -1.23 \\
\hline & & 12774.38 & 2 & 294.0151 & & 0.001 & 1.47 & -2.72 \\
\hline & & 13364.83 & 2 & 299.2112 & & 0.008 & 11.69 & -1.80 \\
\hline & & 14091.37 & 3 & 305.8626 & & 0.013 & 18.97 & -1.57 \\
\hline & & 14848.05 & 4 & 313.1116 & & 0.116 & 169.19 & -0.60 \\
\hline & & 15222.57 & 2 & 316.8282 & & 0.073 & 106.47 & -0.79 \\
\hline & & 19108.87 & 4 & 361.3329 & & 0.002 & 2.94 & -2.24 \\
\hline & & 19410.66 & 2 & 365.3178 & & 0.003 & 4.34 & -2.06 \\
\hline & & 21123.66 & 3 & 389.7132 & & 0.002 & 2.94 & -2.17 \\
\hline & & 21303.36 & 2 & 392.4625 & & 0.001 & 1.47 & -2.47 \\
\hline & & 23317.60 & 2 & 426.1613 & & 0.003 & 4.34 & -1.93 \\
\hline & & 23984.58 & 3 & 438.6328 & & 0.001 & 1.47 & -2.37 \\
\hline & & 25601.55 & 4 & 472.1287 & & 0.003 & 4.34 & -1.84 \\
\hline & & 27350.96 & 3 & 514.6484 & & 0.002 & 2.94 & -1.93 \\
\hline & & 28139.52 & 3 & 536.4245 & & 0.002 & 2.94 & -1.90 \\
\hline & & 29394.30 & 4 & 575.1486 & & 0.003 & 4.34 & -1.67 \\
\hline
\end{tabular}

${ }^{a}$ From Van Kleef \& Klinkenberg (1961).

${ }^{b}$ Wavelengths in air are deduced from experimental level values.

${ }^{c}$ From Ivarsson et al. (2003) ${ }^{d}$ Branching fractions calculated using the HFR + CP method (see text).

${ }^{e}$ Values obtained by combining calculated BFs and experimental lifetimes given in the first column and taken from:

${ }^{f}$ This work.

${ }^{g}$ Kwiatkowski et al. (1984).

${ }^{h}$ Ivarsson et al. (2003). 
P. Quinet et al.: Transition probabilities and lifetimes in Os I and Os II, Online Material p 5

Table 6. Branching fractions $(B F)$, transition probabilities $\left(g A\right.$, in $\left.10^{6} \mathrm{~s}^{-1}\right)$ and oscillator strengths $(\log g f)$ for transitions depopulating the odd-parity levels of Os II.

\begin{tabular}{|c|c|c|c|c|c|c|c|c|c|c|}
\hline \multirow{2}{*}{$\begin{array}{l}\text { Upper level }^{a} \\
\text { Energy }\left(\mathrm{cm}^{-1}\right)\end{array}$} & \multirow[t]{2}{*}{$\overline{J J}$} & \multirow{2}{*}{$\begin{array}{r}\text { Lower level }{ }^{a} \\
\text { Energy }\left(\mathrm{cm}^{-1}\right)\end{array}$} & \multirow[t]{2}{*}{ 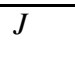 } & \multirow[t]{2}{*}{$\overline{c \lambda(\mathrm{nm})^{b}}$} & \multicolumn{2}{|c|}{$\overline{\text { Experiment }^{c}}$} & \multicolumn{4}{|c|}{ This work } \\
\hline & & & & & $B F$ & $g A$ & $B F^{d}$ & $g A^{e}$ & $\log g f^{e}$ & $C F^{h}$ \\
\hline 39389.49 & $7 / 2$ & 0.00 & $9 / 2$ & 253.7986 & 0.914 & 107.5 & 0.307 & 37.2 & -1.44 & -0.030 \\
\hline \multirow[t]{6}{*}{$\tau=66(6)^{f} \mathrm{~ns}$} & & 3593.15 & $7 / 2$ & 279.2758 & & & 0.012 & 1.4 & -2.79 & 0.004 \\
\hline & & 3928.94 & $5 / 2$ & 281.9205 & 0.003 & 0.4 & 0.025 & 3.0 & -2.45 & -0.015 \\
\hline & & 7891.93 & $5 / 2$ & 317.3931 & 0.006 & 0.7 & 0.275 & 33.3 & -1.30 & 0.128 \\
\hline & & 11654.08 & $5 / 2$ & 360.4471 & & & 0.198 & 24.0 & -1.33 & 0.185 \\
\hline & & 13203.88 & $7 / 2$ & 381.7808 & & & 0.002 & 0.2 & -3.36 & -0.024 \\
\hline & & 13414.80 & $5 / 2$ & 384.8810 & 0.024 & 2.8 & 0.171 & 20.7 & -1.34 & -0.127 \\
\hline \multirow{5}{*}{$\begin{array}{l}41282.95 \\
{[\tau=122 \mathrm{~ns}]}\end{array}$} & $9 / 2$ & 0.00 & $9 / 2$ & 242.1572 & & & 0.855 & 70.1 & -1.21 & -0.211 \\
\hline & & 3593.15 & $7 / 2$ & 265.2448 & & & 0.004 & 0.3 & -3.50 & -0.003 \\
\hline & & 11459.90 & $7 / 2$ & 335.2148 & & & 0.057 & 4.7 & -2.10 & 0.114 \\
\hline & & 13203.88 & $7 / 2$ & 356.0355 & & & 0.044 & 3.6 & -2.16 & -0.179 \\
\hline & & 17242.26 & $7 / 2$ & 415.8442 & & & 0.010 & 0.8 & -2.68 & 0.084 \\
\hline \multirow{11}{*}{$\begin{array}{l}43802.36 \\
\tau=5.3(4)^{f} \mathrm{~ns}\end{array}$} & $7 / 2$ & 0.00 & $9 / 2$ & 228.2278 & 0.687 & 930.9 & 0.760 & 1147.2 & -0.05 & 0.331 \\
\hline & & 3593.15 & $7 / 2$ & 248.6242 & 0.230 & 311.5 & 0.155 & 226.4 & -0.68 & 0.097 \\
\hline & & 3928.94 & $5 / 2$ & 250.7181 & 0.015 & 20.4 & 0.016 & 24.1 & -1.64 & -0.020 \\
\hline & & 7891.93 & $5 / 2$ & 278.3885 & 0.026 & 35.1 & 0.010 & 15.1 & -1.76 & -0.018 \\
\hline & & 11459.90 & $7 / 2$ & 309.1013 & & & 0.004 & 6.3 & -2.04 & -0.007 \\
\hline & & 11654.08 & $5 / 2$ & 310.9684 & & & 0.014 & 21.1 & -1.51 & -0.103 \\
\hline & & 13203.88 & $7 / 2$ & 326.7194 & & & 0.027 & 40.7 & -1.19 & 0.120 \\
\hline & & 13414.80 & $5 / 2$ & 328.9873 & & & 0.008 & 12.1 & -1.71 & 0.033 \\
\hline & & 15605.58 & $9 / 2$ & 354.5491 & & & 0.001 & 1.5 & -2.55 & 0.005 \\
\hline & & 17242.26 & $7 / 2$ & 376.3976 & & & 0.001 & 1.5 & -2.50 & -0.017 \\
\hline & & 21590.81 & $9 / 2$ & 450.0899 & & & 0.001 & 1.5 & -2.34 & -0.012 \\
\hline \multirow{6}{*}{$\begin{array}{l}44315.40 \\
\tau=5.1(4)^{f} \mathrm{~ns}\end{array}$} & $9 / 2$ & 0.00 & $9 / 2$ & 225.5853 & & & 0.882 & 1729.4 & 0.12 & 0.454 \\
\hline & & 3593.15 & $7 / 2$ & 245.4917 & & & 0.011 & 21.6 & -1.71 & 0.012 \\
\hline & & 11459.90 & $7 / 2$ & 304.2745 & & & 0.038 & 74.5 & -0.98 & -0.118 \\
\hline & & 13203.88 & $7 / 2$ & 321.3315 & & & 0.031 & 60.8 & -1.03 & 0.199 \\
\hline & & 17242.26 & $7 / 2$ & 369.2647 & & & 0.007 & 13.7 & -1.55 & -0.096 \\
\hline & & 17688.64 & $11 / 2$ & 375.4553 & & & 0.001 & 2.0 & -2.37 & -0.075 \\
\hline \multirow{8}{*}{$\begin{array}{l}46157.19 \\
\tau=5.6(5)^{g} \mathrm{~ns}\end{array}$} & $3 / 2$ & 3928.94 & $5 / 2$ & 236.7360 & 0.863 & 616.6 & 0.880 & 628.5 & -0.28 & 0.337 \\
\hline & & 5592.05 & $3 / 2$ & 246.4425 & & & 0.014 & 10.0 & -2.04 & 0.014 \\
\hline & & 6636.57 & $1 / 2$ & 252.9564 & 0.031 & 22.4 & 0.029 & 20.7 & -1.70 & -0.021 \\
\hline & & 7891.93 & $5 / 2$ & 261.2556 & 0.028 & 19.8 & 0.008 & 5.7 & -2.23 & 0.006 \\
\hline & & 13136.61 & $3 / 2$ & 302.7533 & & & 0.008 & 5.7 & -2.11 & -0.016 \\
\hline & & 13414.80 & $5 / 2$ & 305.3257 & & & 0.001 & 0.7 & -3.01 & 0.001 \\
\hline & & 17424.39 & $3 / 2$ & 347.9347 & & & 0.018 & 12.8 & -1.63 & 0.093 \\
\hline & & 17569.40 & $5 / 2$ & 349.6996 & & & 0.026 & 18.6 & -1.47 & -0.072 \\
\hline \multirow{11}{*}{$\begin{array}{l}46373.51 \\
\tau=6.0(6)^{f} \mathrm{~ns}\end{array}$} & $5 / 2$ & 3593.15 & $7 / 2$ & 233.6805 & 0.773 & 828.5 & 0.772 & 772.0 & -0.20 & 0.342 \\
\hline & & 3928.94 & $5 / 2$ & 235.5293 & 0.113 & 121.5 & 0.080 & 80.0 & -1.18 & 0.052 \\
\hline & & 5592.05 & $3 / 2$ & 245.1352 & 0.038 & 41.0 & 0.057 & 57.0 & -1.29 & -0.041 \\
\hline & & 7891.93 & $5 / 2$ & 259.7869 & & & 0.012 & 12.0 & -1.91 & 0.014 \\
\hline & & 11459.90 & $7 / 2$ & 286.3372 & & & 0.013 & 13.0 & -1.80 & 0.025 \\
\hline & & 11654.08 & $5 / 2$ & 287.9387 & & & 0.006 & 6.0 & -2.13 & -0.024 \\
\hline & & 13136.61 & $3 / 2$ & 300.7828 & & & 0.001 & 1.0 & -2.87 & 0.003 \\
\hline & & 13203.88 & $7 / 2$ & 301.3928 & & & 0.007 & 7.0 & -2.02 & -0.035 \\
\hline & & 13414.80 & $5 / 2$ & 303.3216 & & & 0.037 & 37.0 & -1.29 & 0.084 \\
\hline & & 17242.26 & $7 / 2$ & 343.1756 & & & 0.001 & 1.0 & -2.75 & 0.018 \\
\hline & & 17569.40 & $5 / 2$ & 347.0733 & & & 0.008 & 8.0 & -1.84 & 0.043 \\
\hline
\end{tabular}


P. Quinet et al.: Transition probabilities and lifetimes in Os I and Os II, Online Material p 6

Table 6. continued.

\begin{tabular}{|c|c|c|c|c|c|c|c|c|c|c|}
\hline \multirow{2}{*}{$\begin{array}{l}\text { Upper level }{ }^{a} \\
\text { Energy }\left(\mathrm{cm}^{-1}\right)\end{array}$} & \multirow[t]{2}{*}{$\overline{J J}$} & \multirow{2}{*}{$\begin{array}{c}\text { Lower level }^{a} \\
\text { Energy }\left(\mathrm{cm}^{-1}\right)\end{array}$} & \multirow[t]{2}{*}{$\overline{J J}$} & \multirow[t]{2}{*}{$\bar{~} \lambda(\mathrm{nm})^{b}$} & \multicolumn{2}{|c|}{$\overline{\text { Experiment }^{c}}$} & \multicolumn{4}{|c|}{ This work } \\
\hline & & & & & $B F$ & $g A$ & $B F^{d}$ & $g A^{e}$ & $\log g f^{e}$ & $C F^{h}$ \\
\hline 48128.08 & $1 / 2$ & 5592.05 & $3 / 2$ & 235.0229 & 0.708 & 240.2 & 0.768 & 260.3 & -0.67 & 0.320 \\
\hline \multirow[t]{3}{*}{$\tau=5.9(5)^{g} \mathrm{~ns}$} & & 6636.57 & $1 / 2$ & 240.9399 & 0.083 & 28.1 & 0.099 & 33.5 & -1.54 & -0.118 \\
\hline & & 13136.61 & $3 / 2$ & 285.7000 & & & 0.027 & 9.1 & -1.95 & -0.040 \\
\hline & & 17424.39 & $3 / 2$ & 325.5998 & & & 0.005 & 1.7 & -2.57 & -0.021 \\
\hline 48798.70 & $5 / 2$ & 3928.94 & $5 / 2$ & 222.7980 & 0.606 & 542.7 & 0.484 & 433.4 & -0.49 & -0.155 \\
\hline \multirow[t]{10}{*}{$\tau=6.7(5)^{g} \mathrm{~ns}$} & & 5592.05 & $3 / 2$ & 231.3747 & 0.162 & 145.2 & 0.278 & 248.9 & -0.70 & -0.121 \\
\hline & & 7891.93 & $5 / 2$ & 244.3842 & 0.044 & 39.1 & 0.036 & 32.2 & -1.54 & -0.015 \\
\hline & & 11459.90 & $7 / 2$ & 267.7384 & & & 0.029 & 26.0 & -1.55 & -0.028 \\
\hline & & 11654.08 & $5 / 2$ & 269.1381 & 0.027 & 24.3 & 0.023 & 20.6 & -1.65 & -0.024 \\
\hline & & 13136.61 & $3 / 2$ & 280.3272 & & & 0.001 & 0.9 & -2.97 & 0.001 \\
\hline & & 13414.80 & $5 / 2$ & 282.5313 & & & 0.025 & 22.4 & -1.57 & 0.017 \\
\hline & & 17242.26 & $7 / 2$ & 316.8008 & & & 0.001 & 0.9 & -2.87 & 0.005 \\
\hline & & 17424.39 & $3 / 2$ & 318.6400 & & & 0.056 & 50.1 & -1.12 & -0.119 \\
\hline & & 17569.40 & $5 / 2$ & 320.1196 & & & 0.008 & 7.2 & -1.96 & 0.014 \\
\hline & & 19985.93 & $7 / 2$ & 346.9690 & & & 0.003 & 2.7 & -2.31 & -0.013 \\
\hline 49149.39 & $7 / 2$ & 0.00 & $9 / 2$ & 203.3959 & & & 0.014 & 16.7 & -1.98 & 0.005 \\
\hline \multirow[t]{11}{*}{$\tau=6.7(6)^{f} \mathrm{~ns}$} & & 3593.15 & $7 / 2$ & 219.4403 & & & 0.696 & 831.0 & -0.22 & -0.259 \\
\hline & & 3928.94 & $5 / 2$ & 221.0700 & & & 0.011 & 13.1 & -2.02 & -0.006 \\
\hline & & 7891.93 & $5 / 2$ & 242.3068 & & & 0.175 & 208.9 & -0.73 & -0.125 \\
\hline & & 11459.90 & $7 / 2$ & 265.2470 & & & 0.009 & 10.7 & -1.95 & -0.011 \\
\hline & & 11654.08 & $5 / 2$ & 266.6207 & & & 0.012 & 14.3 & -1.82 & -0.024 \\
\hline & & 13203.88 & $7 / 2$ & 278.1168 & & & 0.003 & 3.6 & -2.38 & -0.009 \\
\hline & & 13414.80 & $5 / 2$ & 279.7584 & & & 0.011 & 13.1 & -1.81 & 0.015 \\
\hline & & 15605.58 & $9 / 2$ & 298.0306 & & & 0.001 & 1.2 & -2.80 & 0.019 \\
\hline & & 17569.40 & $5 / 2$ & 316.5646 & & & 0.048 & 57.3 & -1.06 & -0.154 \\
\hline & & 19590.91 & $5 / 2$ & 338.2153 & & & 0.002 & 2.4 & -2.38 & 0.017 \\
\hline & & 19985.93 & $7 / 2$ & 342.7965 & & & 0.002 & 2.4 & -2.37 & 0.0143 \\
\hline 51770.38 & $5 / 2$ & 3593.15 & $7 / 2$ & 207.5008 & & & 0.001 & 1.0 & -3.19 & 0.000 \\
\hline \multirow[t]{13}{*}[\tau=8.2\mathrm{ns}]{} & & 3928.94 & $5 / 2$ & 208.9573 & & & 0.048 & 35.5 & -1.63 & -0.011 \\
\hline & & 5592.05 & $3 / 2$ & 216.4838 & & & 0.562 & 413.6 & -0.54 & -0.204 \\
\hline & & 7891.93 & $5 / 2$ & 227.8319 & & & 0.148 & 109.1 & -1.07 & 0.037 \\
\hline & & 11459.90 & $7 / 2$ & 247.9995 & & & 0.028 & 20.7 & -1.72 & -0.023 \\
\hline & & 11654.08 & $5 / 2$ & 249.2001 & & & 0.062 & 45.3 & -1.37 & 0.034 \\
\hline & & 13136.61 & $3 / 2$ & 258.7635 & & & 0.004 & 3.2 & -2.49 & 0.005 \\
\hline & & 13203.88 & $7 / 2$ & 259.2149 & & & 0.001 & 1.0 & -3.00 & -0.002 \\
\hline & & 13414.80 & $5 / 2$ & 260.6404 & & & 0.034 & 24.8 & -1.60 & -0.013 \\
\hline & & 17242.26 & $7 / 2$ & 289.5341 & & & 0.001 & 0.8 & -3.00 & 0.005 \\
\hline & & 17424.39 & $3 / 2$ & 291.0696 & & & 0.058 & 42.6 & -1.27 & -0.124 \\
\hline & & 17569.40 & $5 / 2$ & 292.340 & & & 0.004 & 3.1 & -2.40 & 0.006 \\
\hline & & 19590.91 & $5 / 2$ & 310.6670 & & & 0.002 & 1.3 & -2.72 & -0.005 \\
\hline & & 19985.93 & $7 / 2$ & 314.5281 & & & 0.003 & 2.2 & -2.49 & -0.0103 \\
\hline 51951.61 & $9 / 2$ & 0.00 & $9 / 2$ & 192.4868 & 0.259 & 810.7 & 0.182 & 568.7 & -0.50 & 0.117 \\
\hline \multirow[t]{7}{*}{$\tau=3.2(3)^{f} \mathrm{~ns}$} & & 3593.15 & $7 / 2$ & 206.7230 & 0.442 & 1381.7 & 0.562 & 1756.2 & 0.05 & -0.501 \\
\hline & & 11459.90 & $7 / 2$ & 246.8895 & 0.089 & 277.2 & 0.089 & 278.1 & -0.59 & 0.121 \\
\hline & & 13203.88 & $7 / 2$ & 258.0024 & 0.161 & 502.9 & 0.097 & 303.1 & -0.52 & -0.189 \\
\hline & & 15605.58 & $9 / 2$ & 275.0519 & & & 0.011 & 34.3 & -1.41 & -0.058 \\
\hline & & 17242.26 & $7 / 2$ & 288.0223 & & & 0.012 & 37.5 & -1.33 & 0.047 \\
\hline & & 17688.64 & $11 / 2$ & 291.7749 & & & 0.009 & 28.2 & -1.44 & 0.166 \\
\hline & & 21590.81 & $9 / 2$ & 329.2772 & & & 0.002 & 6.2 & -2.00 & 0.023 \\
\hline
\end{tabular}


Table 6. continued.

\begin{tabular}{|c|c|c|c|c|c|c|c|c|c|c|}
\hline \multirow{2}{*}{$\begin{array}{l}\text { Upper level }^{a} \\
\text { Energy }\left(\mathrm{cm}^{-1}\right)\end{array}$} & \multirow[t]{2}{*}{$\overline{J J}$} & \multirow{2}{*}{$\begin{array}{r}\text { Lower level }{ }^{a} \\
\text { Energy }\left(\mathrm{cm}^{-1}\right)\end{array}$} & \multirow[t]{2}{*}{$\overline{J J}$} & \multirow[t]{2}{*}{$\overline{c \lambda(\mathrm{nm})^{b}}$} & \multicolumn{2}{|c|}{ Experiment $^{c}$} & \multicolumn{4}{|c|}{ This work } \\
\hline & & & & & $B F$ & $g A$ & $B F^{d}$ & $g A^{e}$ & $\log g f^{e}$ & $C F^{h}$ \\
\hline 52206.48 & $7 / 2$ & 0.00 & $9 / 2$ & 191.5471 & & & 0.001 & 1.6 & -3.05 & -0.001 \\
\hline \multirow[t]{11}{*}{$\tau=4.9(4)^{f} \mathrm{~ns}$} & & 3593.15 & $7 / 2$ & 205.6391 & 0.440 & 749.6 & - & - & - & 0.000 \\
\hline & & 3928.94 & $5 / 2$ & 207.0696 & 0.415 & 706.9 & 0.632 & 1031.8 & -0.18 & -0.364 \\
\hline & & 7891.93 & $5 / 2$ & 225.5896 & & & 0.002 & 3.3 & -2.60 & 0.001 \\
\hline & & 11459.90 & $7 / 2$ & 245.3451 & & & 0.060 & 98.0 & -1.05 & -0.051 \\
\hline & & 11654.08 & $5 / 2$ & 246.5200 & & & 0.022 & 35.9 & -1.48 & 0.044 \\
\hline & & 13203.88 & $7 / 2$ & 256.3163 & & & 0.112 & 182.8 & -0.74 & 0.137 \\
\hline & & 13414.80 & $5 / 2$ & 257.7101 & & & 0.037 & 60.4 & -1.22 & -0.044 \\
\hline & & 15605.58 & $9 / 2$ & 273.1365 & & & 0.047 & 76.7 & -1.07 & 0.112 \\
\hline & & 17569.40 & $5 / 2$ & 288.6233 & 0.028 & 48.3 & 0.018 & 29.4 & -1.43 & -0.055 \\
\hline & & 19590.91 & $5 / 2$ & 306.5129 & & & 0.001 & 1.6 & -2.65 & 0.004 \\
\hline & & 21590.81 & $9 / 2$ & 326.5360 & & & 0.005 & 8.2 & -1.88 & -0.024 \\
\hline & $7 / 2$ & 0.00 & $9 / 2$ & 183.8936 & & & 0.001 & 2.0 & -2.99 & 0.001 \\
\hline \multirow{13}{*}{$\tau=4.0(4)^{f} \mathrm{~ns}$} & & 3593.15 & $7 / 2$ & 196.9042 & & & 0.023 & 46.0 & -1.57 & 0.013 \\
\hline & & 3928.94 & $5 / 2$ & 198.2148 & & & 0.329 & 658.0 & -0.41 & -0.282 \\
\hline & & 7891.93 & $5 / 2$ & 215.0447 & & & 0.095 & 190.0 & -0.88 & -0.103 \\
\hline & & 11459.90 & $7 / 2$ & 232.9235 & & & 0.076 & 152.0 & -0.91 & 0.057 \\
\hline & & 11654.08 & $5 / 2$ & 233.9822 & & & 0.011 & 22.0 & -1.74 & 0.031 \\
\hline & & 13203.88 & $7 / 2$ & 242.7898 & & & 0.230 & 460.0 & -0.39 & -0.228 \\
\hline & & 13414.80 & $5 / 2$ & 244.0400 & & & 0.019 & 38.0 & -1.47 & -0.041 \\
\hline & & 15605.58 & $9 / 2$ & 257.8296 & & & 0.061 & 122.0 & -0.91 & -0.113 \\
\hline & & 17242.26 & $7 / 2$ & 269.1932 & & & 0.015 & 30.0 & -1.49 & -0.025 \\
\hline & & 17569.40 & $5 / 2$ & 271.5858 & & & 0.009 & 18.0 & -1.70 & -0.020 \\
\hline & & 19590.91 & $5 / 2$ & 287.3681 & & & 0.002 & 4.0 & -2.30 & 0.007 \\
\hline & & 19985.93 & $7 / 2$ & 290.6688 & & & 0.001 & 2.0 & -2.60 & 0.002 \\
\hline & & 21590.81 & $9 / 2$ & 304.8967 & & & 0.023 & 46.0 & -1.19 & 0.072 \\
\hline & $5 / 2$ & 3593.15 & $7 / 2$ & 196.6489 & & & 0.057 & 81.4 & -1.33 & -0.094 \\
\hline \multirow[t]{13}{*}{$\tau=4.2(4)^{f} \mathrm{~ns}$} & & 3928.94 & $5 / 2$ & 197.9561 & & & 0.121 & 172.8 & -0.99 & -0.115 \\
\hline & & 5592.05 & $3 / 2$ & 204.6295 & & & 0.002 & 2.9 & -2.74 & 0.004 \\
\hline & & 7891.93 & $5 / 2$ & 214.7401 & & & 0.076 & 108.6 & -1.12 & 0.051 \\
\hline & & 11459.90 & $7 / 2$ & 232.5663 & & & 0.380 & 542.9 & -0.36 & 0.238 \\
\hline & & 11654.08 & $5 / 2$ & 233.6218 & & & 0.013 & 18.6 & -1.82 & -0.029 \\
\hline & & 13136.61 & $3 / 2$ & 242.0069 & & & 0.047 & 67.1 & -1.23 & 0.071 \\
\hline & & 13203.88 & $7 / 2$ & 242.4017 & & & 0.185 & 264.3 & -0.63 & -0.132 \\
\hline & & 13414.80 & $5 / 2$ & 243.6479 & & & 0.001 & 1.4 & -2.90 & -0.001 \\
\hline & & 17242.26 & $7 / 2$ & 268.7162 & & & 0.037 & 52.8 & -1.24 & 0.052 \\
\hline & & 17424.39 & $3 / 2$ & 270.0383 & & & 0.006 & 8.6 & -2.03 & -0.018 \\
\hline & & 17569.40 & $5 / 2$ & 271.1003 & & & 0.006 & 8.6 & -2.03 & -0.005 \\
\hline & & 19590.91 & $5 / 2$ & 286.8246 & & & 0.011 & 15.7 & -1.71 & -0.024 \\
\hline & & 19985.93 & $7 / 2$ & 290.1127 & & & 0.011 & 15.7 & -1.70 & 0.024 \\
\hline
\end{tabular}

${ }^{a}$ Van Kleef \& Klinkenberg (1961) ${ }^{b}$ Wavelengths are given in vacuum below $200.0 \mathrm{~nm}$ and in air above that limit. They are deduced from experimental level values. ${ }^{c}$ Ivarsson et al. (2004) ${ }^{d}$ This work. ${ }^{e}$ Values obtained by combining calculated BFs and experimental lifetimes given in the first column and taken from: ${ }^{f}$ This work and ${ }^{g}$ Ivarsson et al. (2004). Values between brackets are calculated values in this work. ${ }^{h}$ Cancellation factor (see text). A very small value (typically <0.01) of CF means that strong cancellation effects are present in the calculation of the corresponding transition rate. 